\title{
INTERGENERATIONAL HELP AND \\ PUBLIC ASSISTANCE IN EUROPE \\ A CASE of Specialization?
}

Martina Brandt

@ $\boldsymbol{m e a - M a n n h e i m ~ R e s e a r c h ~ I n s t i t u t e ~ f o r ~ t h e ~ E c o n o m i c s ~ o f ~ A g i n g ~}$

L13, 17_D-68131 Mannheim_Phone +49 621 181-2773/1862_Fax +49 621 181-1863_www.mea.uni-mannheim.de 


\title{
INTERGENERATIONAL HELP AND PUBLIC ASSISTANCE IN EUROPE
}

A Case of Specialization?

\author{
Martina Brandt
}

The comparative analysis of intergenerational support patterns based on SHARE, the Survey of Health, Ageing, and Retirement in Europe, with about 30.000 respondents from eleven European countries reveals a distinct geographical distribution of private support patterns: In Northern Europe help between parents and children is very common, but typically little time-consuming. The contrary is true for Southern Europe, where comparably few support relations are very intense in terms of time. Central Western Europe lies in-between with average transfer rates and intensities. Using multilevel modeling, these different support patterns can be explained by the prevalence of public assistance according to the specialization hypothesis: With increased public transfers and social services, sporadic help is more likely (crowding in), and less time consuming support between generations (crowding out) occurs. Accordingly, most support is provided voluntarily in Northern Europe, whereas it is more often perceived as obligatory in Continental and Mediterranean countries.

Keywords: Generations, Social Policy, Support, Welfare State 


\section{WHY STUDY INTERGENERATIONAL HELP?}

Population ageing already is one of the foremost challenges for European societies today, and it will affect more and more countries in future. The balance between old and young is rapidly changing in all industrialized societies and ever less young people will have to care for ever more frail elderly, even if the rising number of healthy life years is taken into consideration (Lafortune et al. 2007). Although until now empirical studies have not accounted for a resulting decline of intergenerational solidarity in Western societies (e.g., Arber and AttiasDonfut 2000; Bengtson 2001; Hank 2007; Silverstein et al. 1998), there is growing concern about the future (see e.g., Walker 1999). In recent times of economic crisis and welfare state retrenchment, the family might become ever more important as a personal 'safety net' while the private resources to support relatives financially and practically are declining. Different social systems have taken different paths to adjust to expected future developments (see e.g., Anttonen and Sipilä 1996; Saraceno and Keck 2010). It is still unclear, however, how they will cope with upcoming challenges. It is thus vitally important to assess how exactly private and public support interact to maintain and mobilize societal resources efficiently. Particularly the analysis of interrelations between state, market, culture, and support between generations might thus provide clues to a successful 'intergenerational policy' in times of progressive population ageing.

In order to assess transfers between generations in different societies one has to account for the whole spectrum of transfers between parents and children. Most of the extensive sociological literature on intergenerational transfers deals with assistance to the elderly (Spitze and Logan 1992) and focuses on support with activities of daily living (ADL). Personal care is a very important and often intense form of support with great impact on giver and receiver. From a societal point of view however, it occurs rather seldom and only in cases, where a frail person needs extensive support. Practical help with instrumental activities of daily living (IADL) on the contrary is an everyday task that is given, received and 
exchanged in and between all age and social groups, and has an immense productive function for society. From a theoretical point of view, help with IADL is a very flexible indicator for intergenerational support because it may range from one time support for children moving house to the daily preparation of meals for the older parent. Where 'care' in almost every case also includes 'help' tasks, 'help' does not necessarily include 'care'. Both support forms depend on different influencing factors and have to be understood as different functional dimensions of intergenerational solidarity needing to be analyzed separately (Brandt et al. 2009; Walker et al. 1995).

The following analysis, based on the Survey of Health, Ageing and Retirement in Europe (SHARE) 2004, will therefore focus on practical help with household chores (housework, gardening, repairs, transport, paperwork) between respondents $50+(\mathrm{G} 2)$, their adult children $(18+$, G3) and their elderly parents $(64+$, G1) in eleven European countries (Austria AU, Belgium BE, Denmark DK, France FR, Germany DE, Greece GR, Italy IT, the Netherlands NL, Spain ES, Sweden SE, and Switzerland CH). The paper goes beyond recent research by firstly differentiating between the occurrence and the intensity of practical help in different intergenerational directions. It investigates, how likely practical help from the middle aged respondents to their elderly parents and to their adult children is, and analyses the intensity of this support in terms of time. Secondly, different help patterns in Europe are directly traced back to distinct features of welfare state and market by employing multilevel models. To separate such context effects it is vitally important to account for country compositions in terms of individual and familial factors which might impact on intergenerational support. These influences will be addressed in the following section before contextual factors are focused upon in more detail. 


\section{INTERGENERATIONAL SOLIDARITY AND PRACTICAL SUPPORT}

Intergenerational solidarity is a latent construct (van Gaalen and Dykstra 2006) composed of various dimensions expressing a mutual feeling of togetherness. The original model including six dimensions by Bengtson and colleagues (e.g., Bengtson and Roberts 1991) has been modified by Szydlik (2004), who identified structural, normative and consensual solidarity as influencing factors, separating them from outcomes like functional, associational and affectual solidarity. Transfers of time, such as practical help, form part of the functional dimension and are a crucial outcome of intergenerational solidarity.

Various factors are known to influence intergenerational transfers: On the micro level the interplay of resources of the related individuals (opportunities and needs) determine giving and receiving. People who need support are more likely to receive help, and those who have more resources to give support tend to do so more likely (Szydlik 2008). Intergenerational relations are embedded in family structures (meso level) impacting on transfer patterns. Support to frail parents, for example, is often shared between siblings - leading to each single sibling helping less often, but with specific gender differences: Women tend to take over personal care, whereas men take over practical help such as repairs, shopping, support with financial and legal matters etc. (e.g., Finch and Mason 1990; Martin-Matthews and Campbell 1995). The influences of individual and family features on intergenerational support have already been analyzed in great detail in various cultural and political settings (e.g., AttiasDonfut 2003; Kalmijn and Saraceno 2008; Silverstein and Bengtson 1997; Szydlik 2008). These cross sectional single country studies do however not allow for conclusions about the influences of different societal contexts. Contextual structures, namely "conditions of the social, economic and tax system [...], the welfare state, and the labour and housing market, as well as the specific rules and norms of certain institutions and groups" (Szydlik 2008: 100), have an impact on family structures on the one hand and on individual resources of parents and children on the other. Accordingly, they also influence intergenerational transfers. 
Persons with sufficient financial resources are for example able to buy services for themselves but also for other family members in need of assistance - if comprehensive professional services are available. The utilization of external help may result in more time for collective family activities that are not centered to needs (Künemund and Rein 1999). Thus, welfare provision and the services available might not only influence the kind of support exchanged in a social network, but also individual support motives. Cultural norms, welfare state characteristics, and private support patterns are interrelated (see e.g., Triandis 1994; van Oorschot et al. 2008).

Recent comparative research with SHARE data accordingly reveals distinct differences concerning functional intergenerational support patterns in different European countries and welfare regimes (e.g., Albertini et al. 2007; Bonsang 2007; Ogg and Renaut 2006), but does not assess possible explanations empirically. If one wants to test the influences of state, market, and culture, the interplay between all decisive factors addressed above must be accounted for in order to isolate explanatory contributions of specific features. Thus, influences known from previous research such as resources of the givers and receivers (e.g., health, education, income, age) as well as family structures (e.g., number of children, siblings, grandchildren, and stepchildren) are controlled for in the following analyses of contextual impacts on help between generations.

\section{SPECIALIZATION BETWEEN FAMILY AND STATE}

Even if social systems in Europe are slowly converging, cultural and historical differences still have a significant impact on current welfare and family regimes (e.g., Daatland 2001; Daatland and Herlofson 2003a; Reher 1998; Wolf and Ballal 2006). How these differences affect individuals, families and transfers between generations is a very important question, especially in times of population ageing. Aside the popular discussion about "crowding out" and "crowding in" (the substitution or consolidation of private transfers by state interventions; 
e.g., Kohli 1999; Künemund and Rein 1999), recently a third theoretical perspective has evolved, that might be suited to consolidate these two - reputedly - competing hypotheses: Public support in the form of state transfers as well as social services and family support are complementing each other. If this division of labor is related to specific tasks, one could also speak of a "mixed responsibility", a "functional differentiation" or a "specialization" of different supportive instances (e.g., Daatland and Herlofson 2003b; Litwak 1985; Litwak et al. 2003; Motel-Klingebiel et al. 2005). Organizations, such as for example social service providers, are more prone to fulfill technically, legally or medically demanding and regularly scheduled support tasks whereas private helpers know the individual needs and wishes of their relative and are also more likely to give spontaneous support (see Litwak 1985; Litwak et al. 2003).

For example, if public service providers take over regular personal care, family members do not only often assist in organizing this care arrangement but are also more prone to emotionally and instrumentally support their relatives in need on a sporadic basis - a result found across nations (e.g., Bazo and Ancizu 2004) and assessing long term developments (e.g., Lingsom 1997). Different instances fulfill specific tasks appropriate to their resources and competences - an arrangement that possibly not only leads to a higher quantity and quality of support, but also to more personal autonomy for the receivers as well as a relief for the (often female) private caregivers (Daatland 1990; Neal et al. 1997).

Following the specialization hypothesis (Brandt et al. 2009; Deindl and Brandt 2010; Igel et al. 2009) one can presume that sporadic help between parents and children is prevalent in states with generous welfare systems. Social service providers can be entrusted with regular and demanding support if families and people in need have the means to access them. Family members are then enabled to give additional support to their relatives if, when and in which form they like to. 
In countries where little state transfers and market services are offered and the responsibilities for the needy are family centered, support is presumably less likely, but a lot more time consuming when given. When a family member is in need of support and public services are barely available, relatives are forced to support the dependent person, even if this competes with their own plans and wishes. Additionally, carers have less time for helping others when supporting one person intensively (Brandt et al. 2009). In less generous welfare states, sporadic private help might therefore be crowded out by the intensive support tasks for relatives in need.

It is thus hypothesized that (a) the more public support is available in a country, the more likely is sporadic practical help between adult generations, (b) the less public assistance is provided, the more intensive is support between parents and children, and (c) the more public support is available, the more often intergenerational help is a complementing, voluntary task. According to this specialization hypothesis it is thus not necessarily the overall help volume that is affected by social policies (and vice versa), it is rather the patterns of intergenerational help that are expected to vary across different welfare regimes.

\section{DATA AND METHOD}

To examine contextual influences on support patterns between parents and their children in Europe, we use the SHARE data collected in 2004, a representative database about the lives and living conditions of about 30,000 Europeans aged 50 and over in private households (www.share-project.org, for methodological details see Börsch-Supan \& Jürges, 2005). ${ }^{1}$ The question about practical support given reads:

"Now I would like to ask you about the help you have given to others. In the last twelve months, have you personally given any kind of help listed on card 28 to a family member from outside the household, a friend or neighbor?".

\footnotetext{
${ }^{1}$ The sample characteristics are included in Tables A1, A2, and A3.
} 
Forms of help mentioned on card 28 include practical household help, such as help with home repairs, gardening, transportation, shopping, household chores and help with paperwork, such as filling out forms and settling financial or legal matters. Each respondent could name up to three different receivers of these forms of support. The intensity of the practical support given is measured as average time spent helping the respective person per week.

To control for resources of the individuals as well as family structures, we use information the respondents provided about themselves and their natural parents. In the following analyses we include persons aged 50 and above (G2) and the relations to their elderly parents (G1) as well as their adult children (G3) outside the household. ${ }^{2}$

To assess intergenerational help we construct specific parent-child-dyads. These relations are not only theoretically, but also empirically nested in individuals (see also Klein Ikkink et al. 1999), families (household level), and contexts (country level). Logistic and linear four level models are used to assess the impact of micro, meso, and macro level structures on the likelihood and intensity of intergenerational help (for details on multilevel modeling see Hox 2002; Snijders and Bosker 2004). Random intercept models were estimated using the Stata procedures xtmixed and xtlogit (see Rabe-Hesketh and Skrondal 2008). Logistic models (help: yes/no) account for all parent-child-dyads, linear models (log (hours)) apply solely to helpers. In both cases unstandardized coefficients indicate positive effects if greater than zero, and negative effects if lower than zero. $Z$ values allow the assessment of the exact significance level as well as the relative importance of a specific indicator within the model (rank order). Separate models were estimated for each single macro indicator (see next section for details) due to the low number of countries available. The Bayesian information criterion (BIC) assessing the overall model fit (the deviance corrected for the number of first level observations and estimated parameters) is used to compare separate models, with lower BIC values indicating better fit. Finally, individual help motivations such as obligation and

\footnotetext{
${ }^{2}$ The focus is not the "sandwich" or "pivot" position of the respondents (see e.g., Grundy \& Henretta, 2006), but intergenerational relations between different cohorts in Europe.
} 
enjoyment retrieved from the additional SHARE paper questionnaire serve as indicators for a tendency ${ }^{3}$ to complementing voluntary versus necessary obligatory help at national level.

\section{SUPPORT REGIMES IN EUROPE?}

According to the specialization thesis, any kind of public support that leaves the family more resources and freedom to decide on the kind of assistance they provide, may influence if and how family members engage in intergenerational support. It is thus not only public support with IADL, but also financial assistance and personal care by public providers that needs to be addressed in order to measure possible contextual influences on family help. In order to measure public support complementing intergenerational help as analyzed here, all public sources of support for families and people in need of assistance with instrumental and non instrumental activities of daily living are therefore taken into account: Public assistance such as (a) social expenditure directed to all deprived citizens, (b) family expenditure directed to younger families, and (c) health and social service supply directed to people in need of such assistance serve as measures of the public support level provided to citizens in all age groups.

\section{[Figure 1 about here]}

The proportion of family expenditure in a countries' total spending (d) additionally serves as indicator of how important the family is from a political perspective, and how responsibilities for family members in need are divided between private and public (see Table A3 for the detailed numbers). Figure 1 shows the relative positions of the SHARE countries according to the four macro-indicators retrieved from OECD databases (2007a, b, c), forming four distinctive groups: Southern Europe with comparably low social and family assistance,

\footnotetext{
${ }^{3}$ The results are interpreted with caution as the paper questionnaire reached substantially lower response rates than the main CAPI survey.
} 
continental Europe with medium social expenditure and service supply, but comparably extensive efforts for families in France and Belgium, the "pioneers of family policy" (Pfenning and Bahle 2000: 2) as well as Austria. In the socio-democratic regimes (EspingAndersen 1990) Denmark and Sweden, the state assumes comprehensive responsibility for all citizens in need of assistance. These Scandinavian countries offer the most comprehensive public support for families and people in need. According to the specialization hypothesis, these regions should thus form different 'support regimes'. We will now test this hypothesis by analyzing patterns of practical help between children to parents, using exactly the variation in culture and welfare policies in the European 'natural laboratory'.

\section{HELP TO OLDER PARENTS IN EUROPE}

[Figure 2 about here]

Family and social policies follow a North-South gradient with high expenditure and services in the North, medium public spending and service provision in Central Western Europe and low public transfers in the South. A similar North-South distribution accounts for the number of respondents (G2) who help their parents (G1): The likelihood of upwards intergenerational help in Europe ranges from 37 percent of all respondent-parent-dyads in Denmark to 13 percent in Spain (Figure 2, a). At first glance this seems surprising, especially if the existence of strong family ties in Southern Europe (Reher 1998) is taken for granted. When intensities are assessed, the contradiction resolves at least partly: Helping is around three to four times more intense in the South than in the North considering average weekly hours when only support relations are accounted for (Figure 2, b).

[Figure 3 about here] 
According to bivariate analyses (Figure 3), help to older parents positively correlates with contextual structures such as expenditure, the relevance of the family and social service supply in Europe. The more public transfers and services, the more help relations with parents exist in a country. Before and after controlling for decisive factors on the dyadic, personal and household level (see Table 1 for covariates) ${ }^{4}$, social services exhibit the strongest statistically significant correlation with the likelihood of help to parents in a country $(r=0.9)$.

\section{[Figure 4 about here]}

Following our hypotheses, helpers should also react to welfare state characteristics in terms of time they devote to help their parents. Figure 4 shows the correlations between the four indicators and the average amounts of support in help relations per week. The results are reinforcing to the crowding out thesis: The more transfers and services the state and market offer, the less weekly hours of help are given to parents. In Southern Europe (Greece and Italy) help hours range from about seven to nine hours weekly, in Central Western European countries it is less with around four hours in most cases, and in Northern Europe (Denmark, Sweden) as well as Switzerland helpers on average only spend between two and three hours a week assisting their parent.

Table 1 and 2 include the multivariate logistic and linear multilevel model accounting for factors on four levels (dyad, person, household, and country) impacting the likelihood and intensity of help from respondents $50+$ to their older parent. Influencing structures on micro (needs and opportunities of giver and receiver), meso (family structures), and macro level (country context) are thus analyzed jointly, allowing the assessment of their net impact on intergenerational help. As it is not possible to include more than one context variable on the

\footnotetext{
${ }^{4}$ To receive the 'net correlations' in squared brackets, single country models including mean centered variables have been estimated to assess the baseline help levels in each country.
} 
basis of eleven country observations, a separate four level model including all controls was estimated for each macro indicator. The effects of the micro and meso level indicators do not vary substantively between these models, thus the coefficients from a model without macro variable but controlling for the country level variation are shown in Table $1 .^{5}$

The model indicates that needs and opportunities of the potential givers have important consequences for help. The better the health condition and the more socio-economic resources the respondents have, the more likely they support their parent. Time consuming help on the other hand seems to correlate with a bad health condition of the giver. Interpreted as reverse causality, this points to a high pressure situation for the giver when intense help is necessary (see also Arrondel and Mason 2001) - an interpretation supported by many care studies showing that time consuming support places an intense burden on the givers and reduces their physical as well as mental health significantly (for an overview see e.g., Matthews 1988). Finally, help to parents also encompasses more hours on average when children are not working and have lower financial resources.

Furthermore, the parents' resources play an important role: Help seems to be rewarded or stimulated by money and gifts parents transmitted and will possibly transmit to their offspring. But even more important is that children react to the needs of their parents. The older and the worse the health condition, the more likely is time consuming help provided by the child, especially if there is no partner in the parents' household.

\section{[Table 1 about here]}

All these influences are embedded in family structures which also have an impact on if and how intensely help is given. The smaller the geographical distance, the more likely respondents support their parents. It is mostly the respondents living closer who take over the

\footnotetext{
${ }^{5}$ The complete analyses can be retrieved from the author by request.
} 
support responsibilities, but it might also be the case that some move closer to their parents when those become frail and need help. Most help is given from daughters to mothers, and this support is also the most time consuming. In all other relations help is less likely and less intense. Furthermore, having children (G3) plays a competing role with regard to help to the older parent (G1). As supposed, instrumental support seems to be divided between siblings (G2): The more siblings exist, the less likely it is that each single child helps.

\section{[Table 2 about here]}

According to four separate models that control for all these factors (see Table 2), social and family expenditure as well as social services have significant positive effects on intergenerational help to parents. The more public services are provided, the more children $50+$ give help to their older mother or father. This help is however less time consuming when state and market provide comprehensive support. As already indicated in Figure 1 and 2, social service supply is the best predictor of help. The results suggest a specific division of labor or specialization between service providers and respondents. The family takes over sporadic support while public providers are in charge of intense regular ${ }^{6}$ support to elders in need - if possible.

\section{HELP TO ADULT CHILDREN IN EUROPE}

Help to children ranges from two percent of the parent-child-dyads in Spain to around ten percent in Belgium, Denmark, and Sweden (Figure 5, a). The support intensity in terms of time again shows an opposite distribution with around 3 hours in the North of Europe to over ten hours weekly in Mediterranean Europe (Figure 5, b).

\footnotetext{
${ }^{6}$ The same results emerge if the average help intensity in a country is measured as the fraction of daily help.
} 


\section{[Figure 5 about here]}

The analysis of downward help from G2 to G3 reinforces the previous findings: According to the crowding in hypothesis, respondents seem not only more prone to give practical help to their senior parents (G1) but also to their offspring (G3) if the provision of support by the state and at the market is higher (Figure 6). Again, service supply - the closest measureable public supplement for private help - is the best predictor before and after control of the other decisive factors.

\section{[Figure 6 about here]}

On the contrary, and in line with the results concerning help to parents, the more public support in terms of social and family expenditure and social service supply, the less intense is help to children in terms of weekly hours according to Figure 7. After controlling for the country composition (individual resources and family structures, see Table 2) the highest correlation appears between help to children and family expenditure. As the latter is primarily directed to younger persons, this is not a surprising result; the more public transfers adult children (G3) receive in building their own household and family, the less they need intense support with IADL from their parents (G2).

\section{[Figure 7 about here]}

According to the multilevel models in Table 3, help by respondents (G2) to their children (G3) follows similar mechanisms as upwards help to older parents (G1). Personal resources and family structures again account for help variation between dyads, individuals and families. The further away the children live and the less healthy the responding parent is, the 
less likely he or she gives help to each single child. Parents with problems to make ends meet and those who are still working tend to help less likely, and in the latter case also less intensely.

Children who are able to support their parents financially and/or practically often receive help in return. According to the age effects, parents help their children most likely when the latter start their own career and family. Help occurs very likely in younger years, and is rapidly decreasing with the age of the adult child. But still, in phases of unemployment and partnership break-up, parents are there to help their offspring in need. Again, the living distance is one of the most important factors to predict intergenerational help and its intensity.

\section{[Table 3 about here]}

Gender effects are somewhat less evident than in the analysis of help to parents: Fathers seem to be as likely to help their children as mothers to support their daughters. The average weekly support intensity however is highest in female dyads. The more children (G3) respondents have the less likely and intensely they tend to help each single child. More grandchildren (G4) on the other hand lead to more help with household chores and administrative issues directed to the young families. Stepchildren are less likely to get instrumental support but if they do, it is just as intense.

\section{[Table 4 about here]}

Once more, controlling for micro and meso level factors, the contextual embeddedness of intergenerational help seems to play a significant role (Table 4): The more public transfers and services, the more likely are respondents to help their children, but the fewer hours this help encompasses. The results concerning intergenerational help to children thus also support 
the specialization hypothesis. Respondents seem to take over sporadic help to their offspring, and to leave more intense forms of support to public providers if social and family expenditure as well as the social service market allow them to do so.

\section{SUPPORT MOTIVES IN EUROPE}

According to our hypotheses, sporadic support is more likely in countries where the state takes over intense and time consuming support tasks. Following the logic of complementarity and specialization, private support should also be exchanged on a voluntary basis more often in these welfare states. To the contrary, in countries where citizens in need receive less support by the state, family members essentially must engage in support, when their relative needs help - which is then more likely perceived as obligatory and inevitable task.

\section{[Figure 8 about here]}

Analyzing support motives of the respondents $50+(\mathrm{G} 2)$, we again find distinctive NorthSouth differences. Feelings of obligation are mainly driving transfers in Southern and Central Europe and joy is the most frequent motive named in the North - especially if the occurrence of both motives is compared. In Denmark for example less than five percent of respondents feel obligated to help, but around 45 percent say they help because they enjoy it. In Spain the relation almost reverses with 45 percent of obligation and around 20 percent of enjoyment (Figure 8$)^{7}$

Overall, more people in the Northern countries enjoy helping than in the conservative welfare states and in familialistic Mediterranean Europe. This may at least partly be due to support alternatives in generous welfare systems where the family is not solely or mainly

\footnotetext{
7 As respondents were able to indicate both motives simultaneously, the different balances should not (only) be due to different cultural norms and answering behaviors.
} 
responsible for help to relatives in need. Figure 9 consequently shows how joyful helping correlates with public support at country level. The more public transfers and services, the more helpers enjoy their engagement - help seems to be not only more likely and less time consuming, but also more voluntary in countries with a comprehensive social service system. The more support family members get from the public social system, the more likely they take over sporadic help and the more often they seem to do it because they enjoy it.

\section{[Figure 9 about here]}

\section{DISCUSSION}

In Western Europe, intergenerational help patterns between parents and children are related to public policies and social services even when individual and family characteristics are taken into account as important influencing factors. The analyses confirm previous research on family solidarity and intergenerational transfers (see e.g., Szydlik 2008): The more resources the givers have and the higher the needs (lack of resources) of the potential receivers are, the more likely intense help is transferred. Time consuming help to older parents is related to bad health of the givers, and thus pointing to high pressure situations when parents become dependent on intense support from their children with little public alternatives existing. Similar results have been found in many studies on personal care, which places a heavy burden on the giver (Matthews 1988).

On the family level we observe that the more potential receivers there are, the less likely is each single person to receive help. The more potential givers there are the more likely help is divided between these. On European average, women help most, but with specific differences between help directions and cohorts. Male respondents do not engage in support to their parents very much, but support their children as likely as the mothers. This might be due to the differences between help tasks for older and younger persons (e.g., housework vs. 
repairs), but also point to an ongoing change of gender roles, with fathers engaged in private help more than before. But nowadays, family obligations are still not equally shared between women and men. The burdens of intense time consuming support still primarily affect daughters, who are also concerned most with competing family obligations and increasingly involved in the labor market. If and how the state is able to influence gender roles in the family is not easily answered. Results suggest that comprehensive public support stimulates male help because men are more likely to give supplementary help if it does not conflict with their own life agenda (Brandt 2009).

Inequalities can not only be found on the individual and family level but also between countries and social systems. Put neutrally, different 'support regimes' emerge in Western Europe: The likelihood of intergenerational help is highest in Northern Europe and gradually decreasing to the Mediterranean. On the other hand help is little time consuming in Sweden and Denmark with two to three hours on average per week increasing to around-the-clock support in Spain, Greece, and Italy. Similar results emerged in various studies concerning different solidarity indicators (e.g., Albertini et al. 2007; Hank 2007; Ogg and Renaut 2006) but these different patterns have never before been directly traced back to the contextual factors driving them.

The empirical analyses of contextual influences on help show, that the more public support the family receives the more likely sporadic help is transferred between children and parents. The public sector takes over more predictable, regular and medically or technically demanding support tasks while family members with personal knowledge about their relative rather provide supplemental practical support. This specific division of labor should have advantages for both giver and receiver. The quantity and the quality of support most likely increases, because everybody takes over the tasks they are best suited for, people in need are not depending solely on their family, and relatives are discharged from obligatory burdensome support. 
It should not be dismissed that this does not only apply for help to older people. The respondents 50+ are also an important source of support for their children - predominantly in the early years of their adult life, but also in periods of special need (e.g., divorce, unemployment). It can thus be deduced that 'active aging', at least in terms of giving intergenerational help, is encouraged by generous social systems.

Over and above, advantages of a specialization between family and state become apparent when analyzing help motives. Whilst obligation is one of the main support motives in Southern Europe, enjoying help is comparably more common in Scandinavia. These 'support cultures' correlate with welfare systems: The more public service provision, the more voluntary support in a country - a fact that might not only positively affect helpers but also receivers.

Even if going beyond recent comparative research, this study unfortunately suffers from limitations. As SHARE data until now only provide a snapshot of the lives of ageing Europeans, disentangling causalities will only be possible when more waves of SHARE become available. Additionally, only respondent information can be employed to measure support between parents and children, a feature that might influence the results substantively (Lin 2008).

Still, it is quite clear: The collaboration between family and state leads to both more comprehensive and manageable private support in a country. In the course of population aging the quantity and quality of support to a growing number of people in need of help and a decreasing number of potential givers can be assured by a generous public service supply. Simultaneously, resources of the elderly are strengthened, leading to longer autonomous lives and more possibilities to support successor generations. Based on these results it is not advisable to overburden children and parents as the main private support source. Generous comprehensive public services and transfers seem to put family and societal life on a footing 
of voluntary solidarity and facilitate the reconciliation of individual and familial resources in an ageing Europe.

\section{ACKNOWLEDGEMENT}

This paper uses data from release 2 of SHARE 2004. The SHARE data collection has been primarily funded by the European Commission through the 5th framework programme (project QLK6-CT-2001-00360 in the thematic programme Quality of Life). Additional funding came from the US National Institute on Ageing (U01 AG09740-13S2, P01 AG005842, P01 AG08291, P30 AG12815, Y1-AG-4553-01 and OGHA 04-064). Data collection in Austria (through the Austrian Science Foundation, FWF), Belgium (through the Belgian Science Policy Office) and Switzerland (through BBW/OFES/UFES) was nationally funded. The SHARE data collection in Israel was funded by the US National Institute on Aging (R21 AG025169), by the German-Israeli Foundation for Scientific Research and Development (G.I.F.), and by the National Insurance Institute of Israel. Further support by the European Commission through the 6th framework program (projects SHARE-I3, RII-CT2006-062193, and COMPARE, CIT5-CT-2005-028857) is gratefully acknowledged. For methodological details see Börsch-Supan \& Jürges 2005.

\section{REFERENCES}

Albertini, M., Kohli, M. and Vogel, C. (2007) 'Intergenerational Transfers of Time and Money in European Families: Common Patterns - Different Regimes?', Journal of European Social Policy 17(4): 319-334.

Anttonen, A. and Sipilä, J. (1996) 'European Social Care Services: Is it Possible to Identify Models?', Journal of European Social Policy 6(2): 87-100.

Attias-Donfut, C. (2003) 'Family Transfers and Cultural Transmissions Between Three Generations in France', in V. L. Bengtson and A. Lowenstein (eds.), Global Aging and Challenges to Families, New York: Aldine de Gruyter, pp. 214-250. 
Arber, S., and Attias-Donfut, C. (eds.) (2000) The Myth of Generational Conflict. The Family and State in Ageing Societies, London: Routledge.

Arrondel, L. and Masson, A. (2001) 'Family Transfers Involving Three Generations', Scandinavian Journal of Economics 103(3): 415-443.

Bazo, M. T. and Ancizu, I. (2004) 'Family and Service Support', in A. Lowenstein and J. Ogg (eds.), OASIS: Old Age and Autonomy - The Role of Service Systems and Intergenerational Family Solidarity, Haifa: University of Haifa, pp. 214-250.

Bengtson, V. L. and Roberts, R. E. (1991) 'Intergenerational Solidarity in Aging Families: An Example of Formal Theory Construction', Journal of Marriage and the Family 53(4): 856-870.

Bengtson, V. L. (2001) 'Beyond the Nuclear Family: The Increasing Importance of Multigenerational Relationships in American Society', Journal of Marriage and Family 63(1): 1-16.

Börsch-Supan, A. and Jürges, H. (eds.) (2005) Health, Ageing and Retirement in Europe Methodology, Mannheim: Mannheim Research Institute for the Economics of Ageing (MEA), University of Mannheim.

Bonsang, E. (2007) 'How do Middle-Aged Children Allocate Time and Money Transfers to Their Older Parents in Europe?', Empirica 34(2): 171-188.

Brandt, M. (2009) Hilfe zwischen Generationen. Ein europäischer Vergleich, Wiesbaden: VS-Verlag für Sozialwissenschaften.

Brandt, M., Haberkern, K. and Szydlik, M. (2009) 'Intergenerational Help and Care in Europe', European Sociological Review 25(5): 585-601.

Daatland, S. O. (1990) ' What are Families for?' On Family Solidarity and the Preference for Help', Ageing and Society, 10(1): 1-15.

Daatland, S. O. (2001) 'Ageing, Families and Welfare Systems: Comparative Perspectives', Zeitschrift für Gerontologie und Geriatrie 34(1): 16-20.

Daatland, S. O. and Herlofson, K. (2003a) “'Lost Solidarity' or 'Changed Solidarity': A Comparative European View of Normative Family Solidarity', Ageing and Society, 23(5): 537-560.

Daatland, S. O. and Herlofson, K. (2003b) 'Families and Welfare States: Substitution or Complementarity', in A. Lowenstein and J. Ogg (eds.), OASIS: Old Age and Autonomy. The Role 
of Service Systems and Intergenerational Family Solidarity. The Final Report, Haifa: University of Haifa, pp. 281-305.

Deindl, C. and Brandt, M. (2010) 'Financial Support and Practical Help Between Older Parents and Their Middle-aged Children in Europe', Ageing and Society, doi:10.1017/S0144686X10001212. Esping-Andersen, G. (1990) The Three Worlds of Welfare Capitalism, Cambridge: Polity Press.

Finch, J. and Mason, J. (1990) 'Filial Obligations and Kin Support for Elderly People', Ageing and Society 10(2): 151-175.

Grundy, E. and Henretta, J. C. (2006) 'Between Elderly Parents and Adult Children: A New Look at the Intergenerational Care Provided by the Sandwich Generation', Ageing and Society 26(5): 707722.

Hank, K. (2007) 'Proximity and Contacts Between Older Parents and Their Adult Children: A European Comparison', Journal of Marriage and Family 69(1): 157-173.

Hox, J. J. (2002) Multilevel Analysis Techniques and Applications, Mahwah, N.J.: Lawrence Erlbaum Associates.

Igel, C., Brandt, M., Haberkern, K. and Szydlik, M. (2009) 'Specialization Between Family and State. Intergenerational Time Transfers in Western Europe', Journal of Comparative Family Studies 40(2): 203-227.

Kalmijn, M. and Saraceno, C. (2008) 'A Comparative Perspective on Intergenerational Support. Responsiveness to Parental Needs in Individualistic and Familialistic Countries', European Societies 10(3): 479-508.

Klein Ikkink, K., van Tilburg, T. and Knipscheer, C. P. (1999) 'Perceived Instrumental Support Exchanges in Relationships between Elderly Parents and Their Adult Children: Normative and Structural Explanations', Journal of Marriage and the Family 61(4): 831-844.

Kohli, M. (1999) 'Private and Public Transfers Between Generations: Linking the Family and the State', European Societies 1(1): 81-104.

Künemund, H. and Rein, M. (1999) 'There is More to Receiving Than Needing: Theoretical Arguments and Empirical Explorations of Crowding in and Crowding out', Ageing and Society 19(1): 93-121. 
Lafortune, G., Balestat, G. and the Disability Study Expert Group Members (2007) 'Trends in Severe Disability Among Elderly People: Assessing the Evidence in 12 OECD Countries and the Future Implications', OECD Health Working Papers No. 26, Paris: Directorate for Employment, Labour and Social Affairs.

Lin, I.-F. (2008) 'Mother and Daughter Reports About Upward Transfers', Journal of Marriage and Family 70(3): 815-827.

Lingsom, S. (1997) The Substitution Issue. Care Policies and Their Consequences for Family Care, Oslo: Norwegian Social Research.

Litwak, E. (1985) Helping the Elderly: Complementary Roles of Informal Networks and Formal Systems, New York: Guilford Press.

Litwak, E., Silverstein, M., Bengtson, V. L. and Wilson Hirst, Y. (2003) 'Theories About Families, Organizations and Social Supports', in V. L. Bengtson and A. Lowenstein (eds.), Global Aging and Challenges to Families, New York: Aldine de Gruyter, pp. 27-53.

Martin-Matthews, A. and Campbell, L. D. (1995) 'Gender Roles, Employment and Informal Care', in S. Arber and J. Ginn (eds.) Connecting Gender and Ageing - A Sociological Approach, Buckingham: Open University Press, pp. 129-143.

Matthews, S. H. (1988) 'The Burdens of Parent Care: A Critical Evaluation of Recent Findings', Journal of Aging Studies 2(2): 157-165.

Motel-Klingebiel, A., Tesch-Römer, C. and von Kondratowitz, H.-J. (2005) 'Welfare States Do not Crowd out the Family: Evidence for Mixed Responsibility From Comparative Analyses', Ageing and Society 25: 863-882.

Neal, M. B., Ingersoll-Dayton, B. and Starrels, M. E. (1997) 'Gender and Relationship Differences in Caregiving Patterns and Consequences Among Employed Caregivers', The Gerontologist 37(6): 804-816.

OECD (2007a) Annual Labour Force Statistics, Retrieved November 7, 2007 [Data download: October 11, 2006], from www.oecd.org/document/48/0,3343,en_21571361_33915056_39095792 _1_1_1_1,00.html\#EmpDB 
OECD (2007b) Social Expenditure Data Base (SOCX), Retrieved May 11, 2007, from http://stats.oecd.org/wbos/default.aspx?datasetcode=SOCX_AGG

OECD (2007c) The Social Expenditure Database: An Interpretative Guide, Retrieved May 11, 2007, from http://stats.oecd.org/OECDStatDownloadFiles/OECDSOCX2007InterpretativeGuide_En.pdf

Ogg, J. and Renaut, S. (2006) 'The Support of Parents in Old Age by Those Born during 1945-1954:

A European Perspective', Ageing and Society 26(5): 723-743.

Pfenning, A. and Bahle, T. (eds.) (2000) Families and Family Policies in Europe. Comparative Perspectives, Frankfurt a. M., New York: Peter Lang.

Rabe-Hesketh, S. and Skrondal, A. (2008) Multilevel and Longitudinal Modeling Using Stata, College Station: Stata Press.

Reher, D. S. (1998) 'Family Ties in Western Europe: Persistent Contrasts', Population and Development Review 24(2): 203-234.

Saraceno, C. and Keck, W. (2010) 'Can we Identify Intergenerational Policy Regimes in Europe?', European Societies 12(5): 675-696.

Silverstein, M. and Bengtson, V. L. (1997) 'Intergenerational Solidarity and the Structure of Adult Child-Parent Relationships in American Families', American Journal of Sociology 103(2): 429460.

Silverstein, M., Burholt, V., Wenger, G. C. and Bengtson, V. L. (1998) 'Parent Child Relations Among Very Old Parents in Wales and the United States: A Test of Modernization Theory', Journal of Aging Studies 12(4): 387-409.

Snijders, T. A. B. and Bosker, R. J. (2004) Multilevel Analysis. An Introduction to Basic and Advanced Multilevel Modeling (repr. ed.), London: Sage.

Spitze, G. and Logan, J. (1992) 'Helping as a Component of Parent-Adult Child Relations', Research on Aging 14(3): 291-312.

Szydlik, M. (2004) 'Inheritance and Inequality: Theoretical Reasoning and Empirical Evidence', European Sociological Review 20(1): 31-45.

Szydlik, M. (2008) 'Intergenerational Solidarity and Conflict', Journal of Comparative Family Studies 39(1): 97-114. 
Triandis, H. C. (1994) Culture and Social Behavior, New York: McGraw-Hill.

van Gaalen, R. I. and Dykstra, P. A. (2006) 'Solidarity and Conflict Between Adult Children and Parents: A Latent Class Analysis’, Journal of Marriage and Family 68(4): 947-960.

van Oorschot, W., Opielka, M. and Pfau-Effinger, B. (eds.) (2008) Culture and Welfare State. Values and Social Policy in Comparative Perspective, Cheltenham, North Hampton: Edward Elgar.

Walker, A. (1999) 'Ageing in Europe. Challenges and Consequences', Zeitschrift für Gerontologie und Geriatrie 32(6): 390-397.

Walker, A. J., Pratt, C. C. and Eddy, L. (1995) 'Informal Caregiving to Aging Family Members: A Critical Review', Family Relations 44(4): 402-411.

Wolf, D. A. and Ballal, S. S. (2006) 'Family Support for Older People in an Era of Demographic Change and Policy Constraints', Ageing and Society 26(5): 693-706. 


\section{FIGURES}

Figure 1: Public social and family assistance

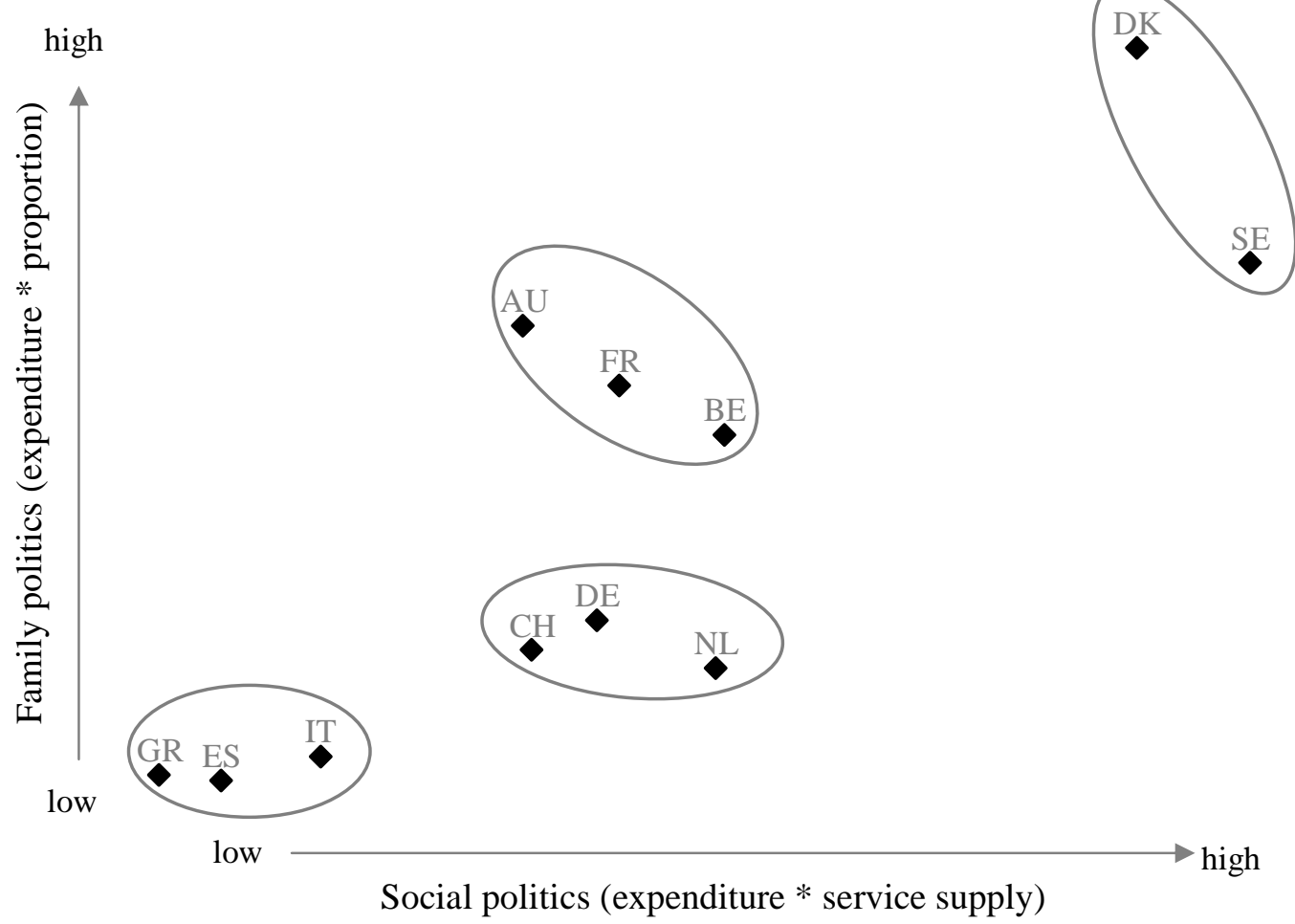

Note: Data retrieved from the OECD (2007a, b, c), own calculations. Social expenditure measured as expenditure for services, transfers and goods in 100 US-Dollar per capita 2002; Service supply measured as percentage of employees in sector $\mathrm{N}$ of the International Standard Industrial Classification; Family expenditure measured as expenditure for services, transfers and goods in 1000 US-Dollar per capita 2002; Proportion of family expenditure measured in percent of a countries' total spending. See Table A3 for numbers. 
Figure 2: Help to parents

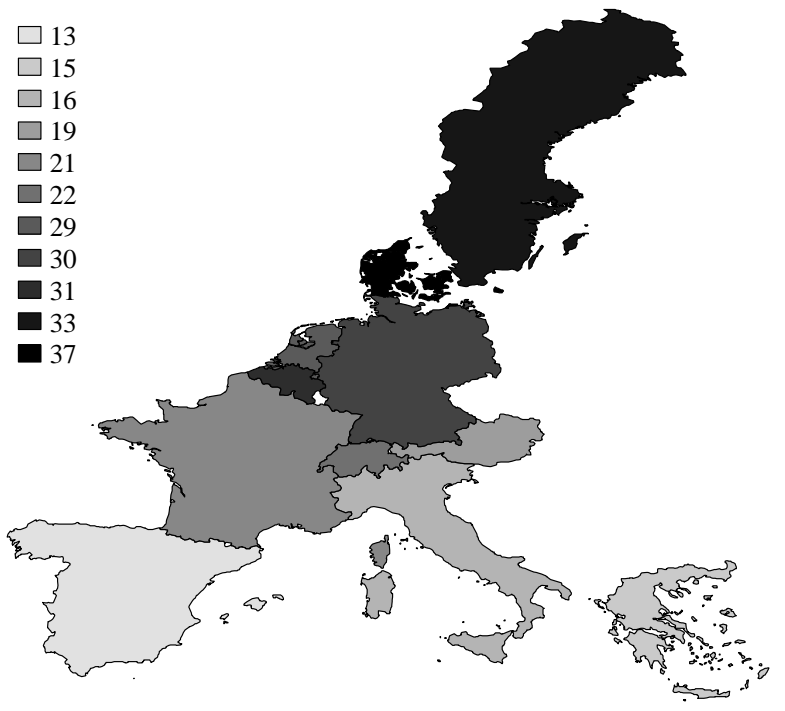

(a) Occurrence

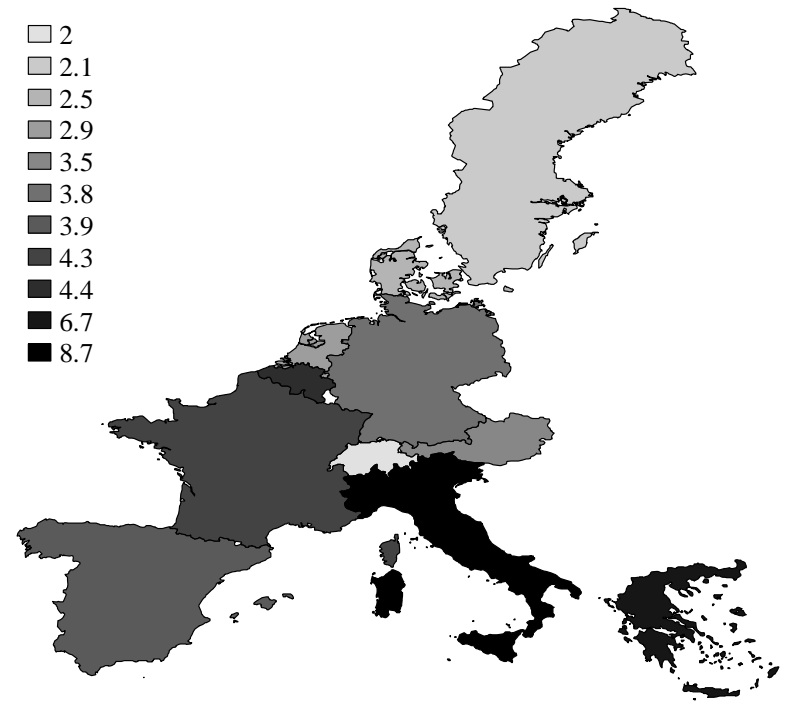

(b) Intensity

Note: SHARE 2004 release 2, own calculations, (a) weighted percentages, $n=7825$ respondent-parent-dyads / (b) average weekly hours, $n=1250$ respondent-parent-dyads. 
Figure 3: Help to parents and context
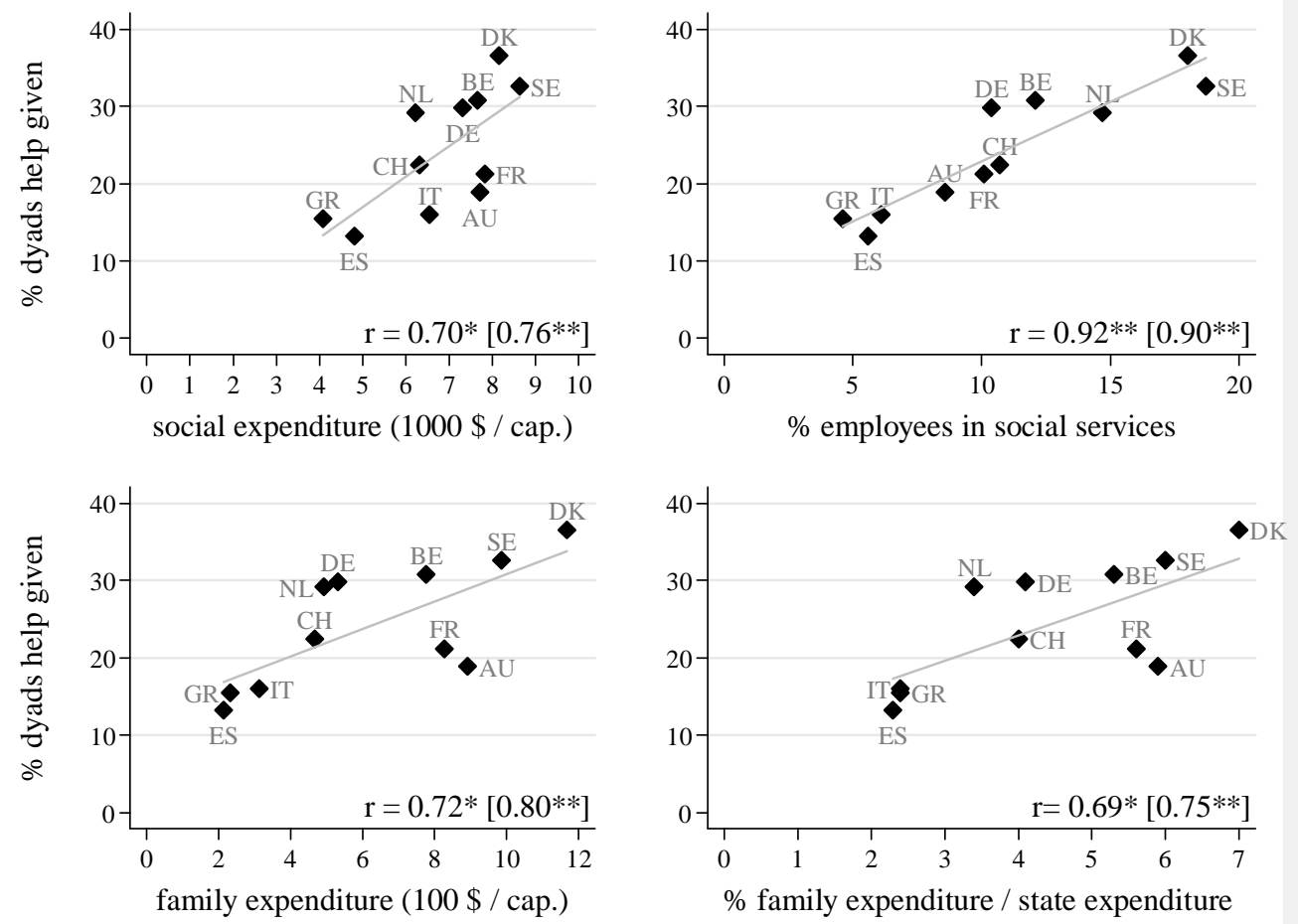

Note: SHARE 2004 release 2, own calculations, weighted / OECD (2007a, b, c). $n=11$ countries. Correlation $r:{ }^{* *} p<.01,{ }^{*} p<.05$ [controlling for covariates indicated in Table 1]. 
Figure 4: Hours of help to parents and context
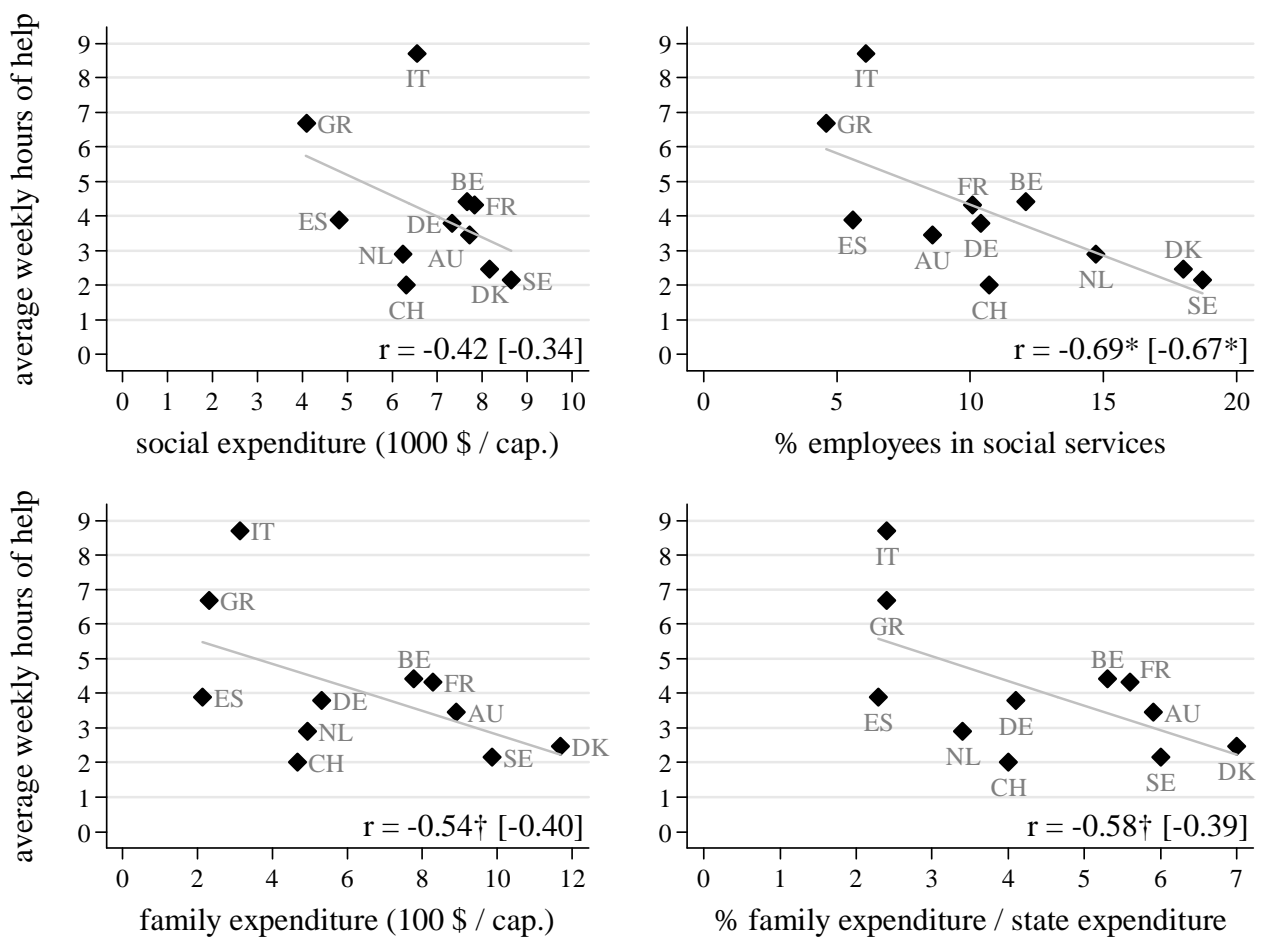

Note: SHARE 2004 release 2, own calculations, weighted / OECD (2007a, b, c). $n=11$ countries. Correlation $r:{ }^{*} p<.05, \dagger p<0.10$ [controlling for covariates indicated in Table 1]. 
Figure 5: Help to children

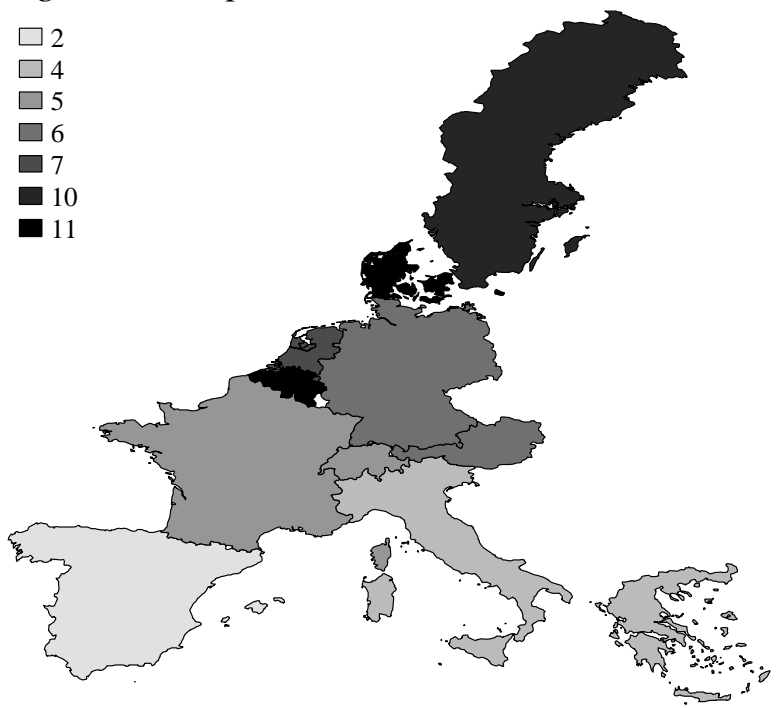

(a) Occurrence

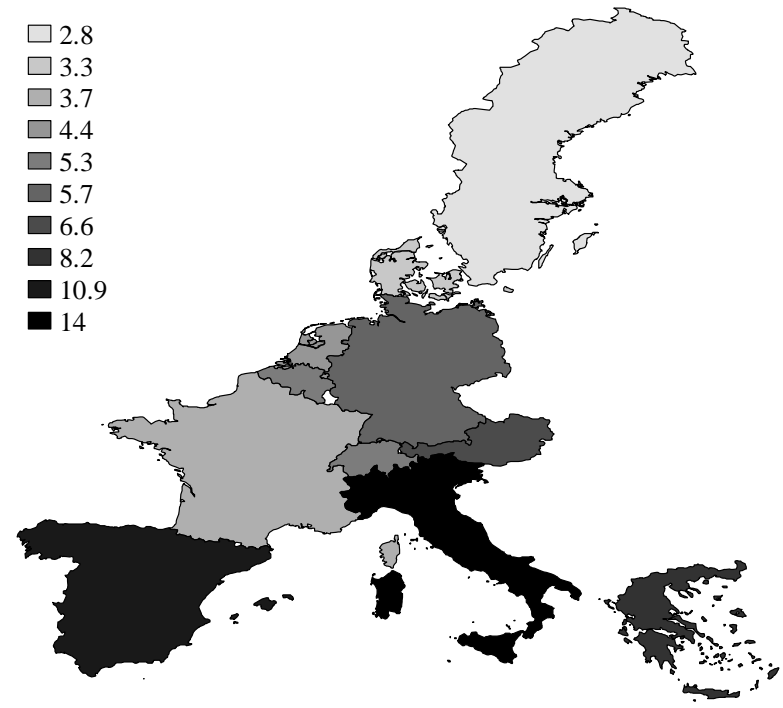

(b) Intensity

Note: SHARE 2004 release 2, own calculations, (a) weighted percentages, $n=40,073$ respondent-child-dyads / (b) average weekly hours, $n=2,584$ respondent-child-dyads. 
Figure 6: Help to children and context
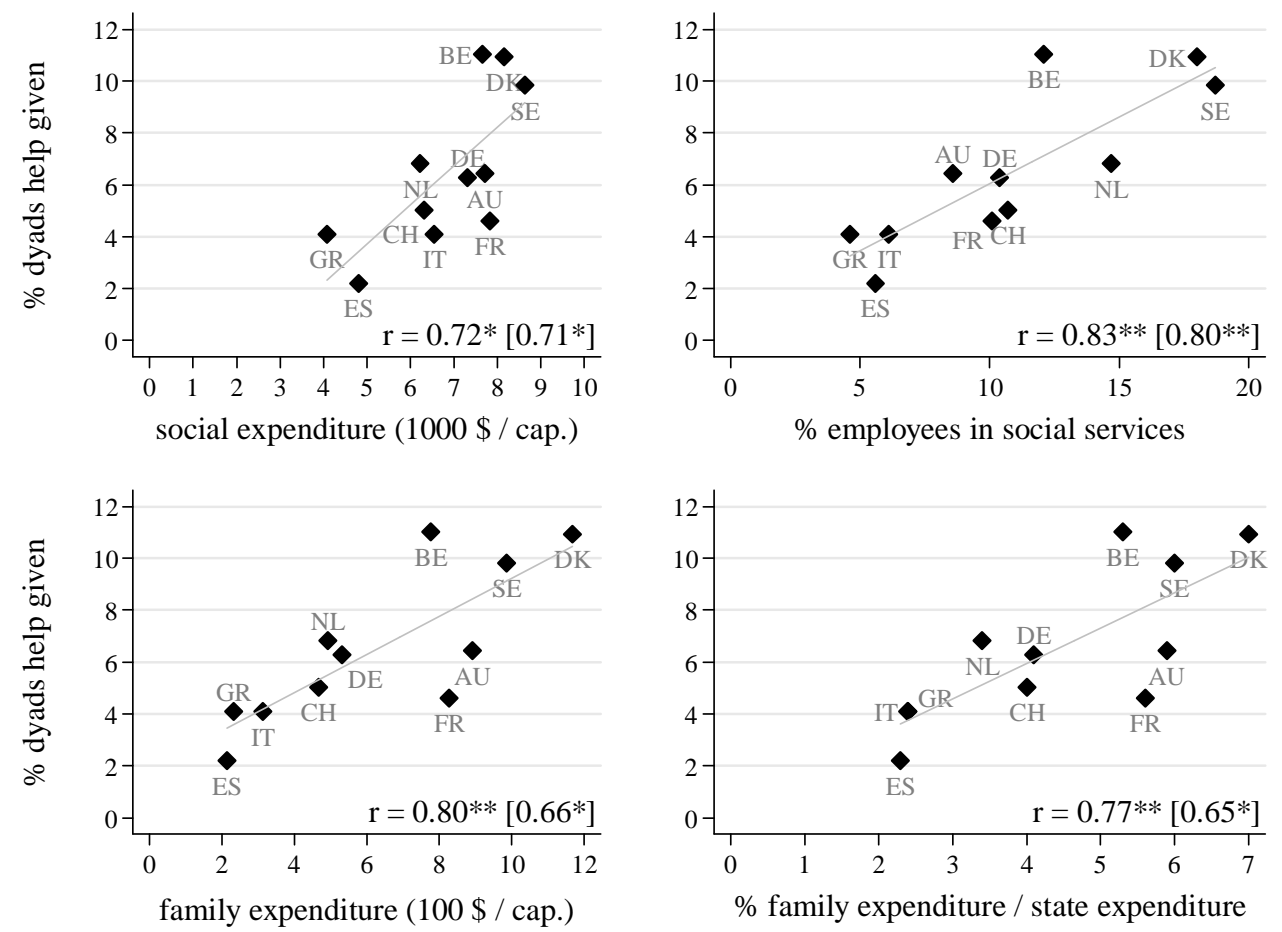

Note: SHARE 2004 release 2, own calculations, weighted / OECD (2007a, b, c). $n=11$ countries. Correlation $r * * p<.01, * p<.05$ [controlling for covariates indicated in Table 3]. 
Figure 7: Hours of help to children and context
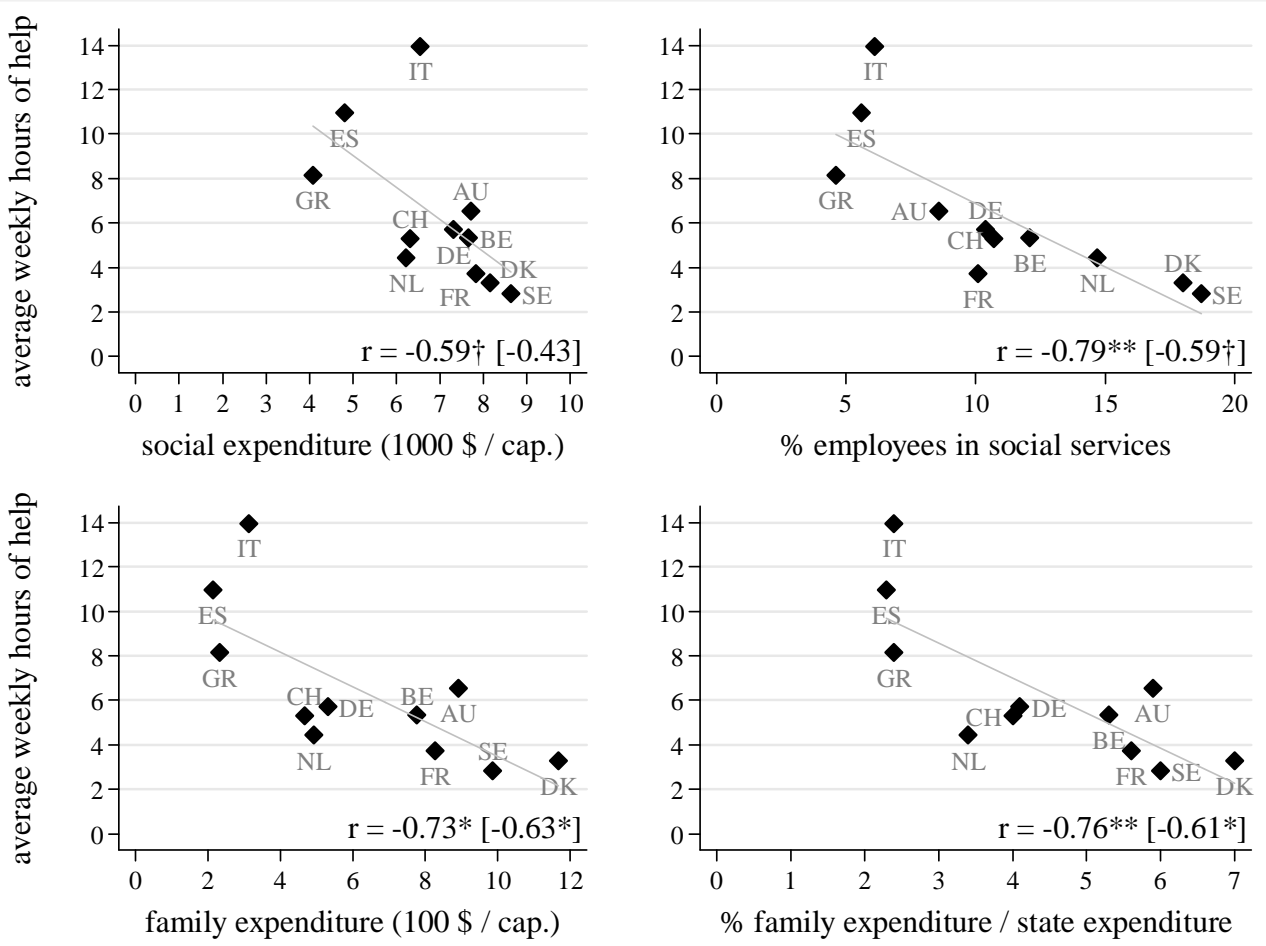

Note: SHARE 2004 release 2, own calculations, weighted / OECD (2007a, b, c). $n=11$ countries. Correlation $r$ : $* *<0.01, * p<.05, \dagger p<0.10$ [controlling for covariates indicated in Table 3]. 
Figure 8: Support motives in Europe

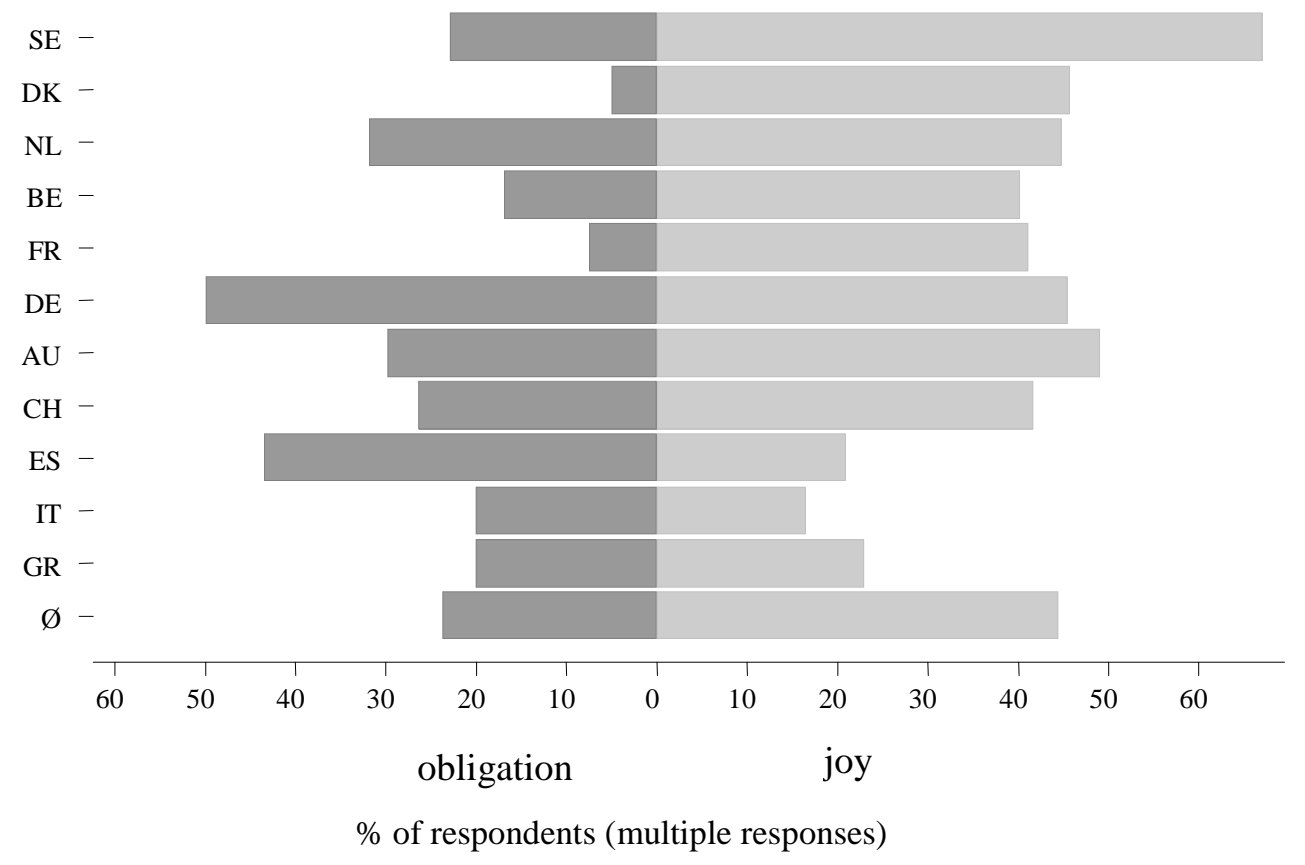

Note: SHARE 2004 release 2, own calculations, weighted. $n=6,144$ persons. 
Figure 9: Joy helping and context
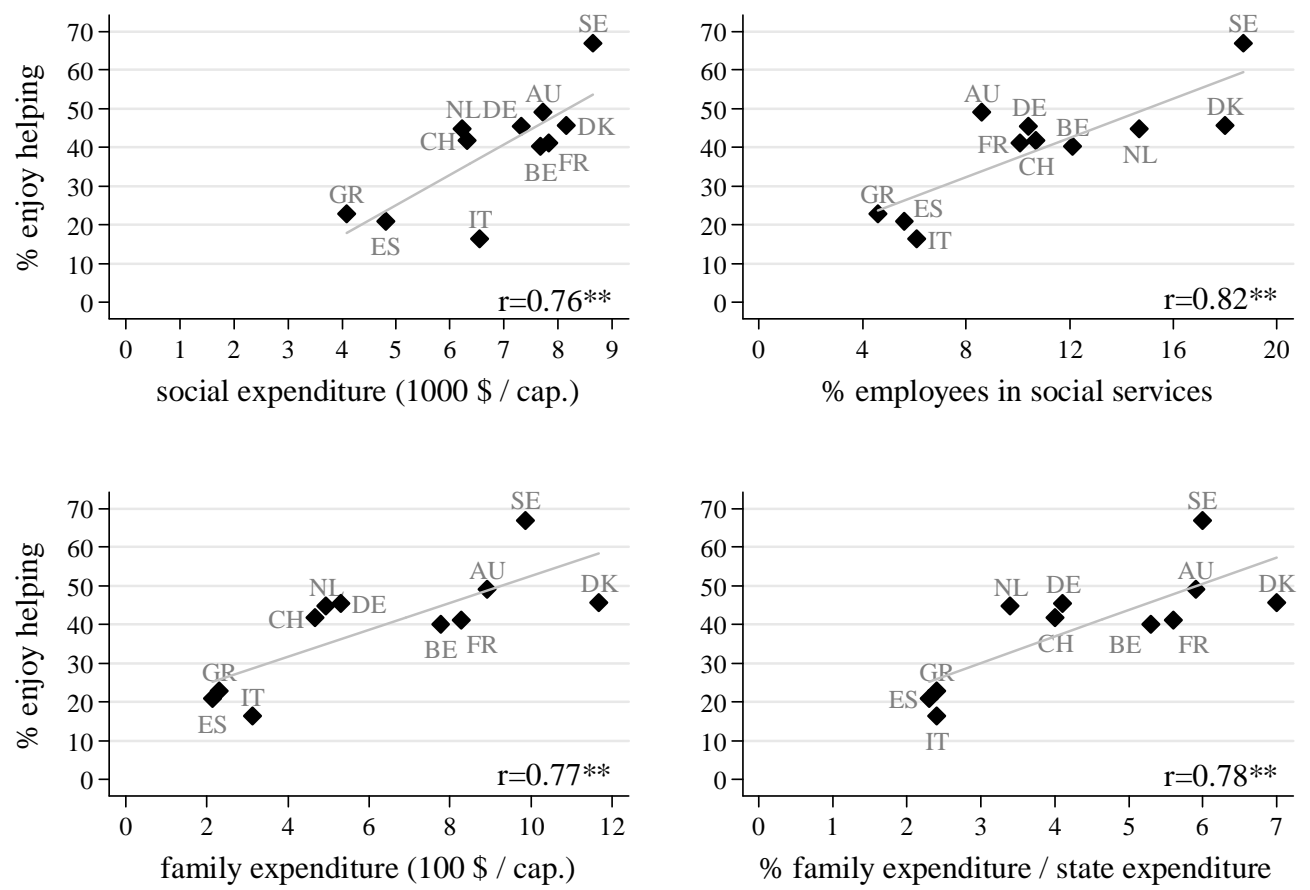

Note: SHARE 2004 release 2, own calculations, weighted / OECD (2007a, b, c). $n=11$ countries. Correlation $r$ : ** $p<0.01$. 


\section{TABLES}

Table 1: Help to parents: Individual and family influences

\begin{tabular}{|c|c|c|c|c|c|}
\hline & & \multicolumn{2}{|c|}{ Likelihood of help } & \multicolumn{2}{|c|}{ Log(hours) of help } \\
\hline & & $\beta^{\mathrm{a}}$ & $z$ & $\beta^{\mathrm{a}}$ & $z$ \\
\hline \multirow{6}{*}{$\begin{array}{l}\text { Resources } \\
\text { responding } \\
\text { child }(G 2)\end{array}$} & Health $(1-5)^{b}$ & $0.15^{*}$ & 2.46 & $-0.17 * *$ & -3.49 \\
\hline & Education low & & & & \\
\hline & medium & $0.30 * *$ & 2.64 & -0.03 & -0.30 \\
\hline & high & $0.43 * *$ & 3.42 & -0.02 & -0.23 \\
\hline & $\begin{array}{l}\text { Household makes ends meet } \\
\text { fairly / easily }\end{array}$ & $0.27 *$ & 2.43 & $-0.22 *$ & -2.38 \\
\hline & Part / full time employed & 0.11 & 1.11 & $-0.37 * *$ & -4.46 \\
\hline \multirow{8}{*}{$\begin{array}{l}\text { Resources } \\
\text { parent (G1) }\end{array}$} & Money to child & $0.80 * *$ & 3.83 & -0.11 & -0.76 \\
\hline & Gift to child & $0.27 * *$ & 2.57 & -0.08 & -1.05 \\
\hline & Chance of bequest $<50 \%$ & & & & \\
\hline & $>=50 \%$ & $0.64 * *$ & 6.31 & -0.07 & -0.92 \\
\hline & unknown & -0.18 & -0.58 & -0.05 & -0.16 \\
\hline & Age (64 - 104) & $0.03 * *$ & 4.07 & $0.03 * *$ & 4.03 \\
\hline & Illness $(1-5)^{\mathrm{c}}$ & $0.23 * *$ & 5.40 & $0.12 * *$ & 3.50 \\
\hline & Partner & $-0.69 * *$ & -6.14 & -0.14 & -1.60 \\
\hline \multirow{7}{*}{$\begin{array}{l}\text { Family } \\
\text { structures }\end{array}$} & Living distance $(0-7)^{\mathrm{d}}$ & $-0.53 * *$ & -13.34 & $-0.18 * *$ & -7.00 \\
\hline & Daughter-mother & & & & \\
\hline & son-mother & $-0.76 * *$ & -7.25 & $-0.37 * *$ & -4.74 \\
\hline & daughter-father & $-1.10^{* *}$ & -7.82 & -0.16 & -1.56 \\
\hline & son-father & $-1.40 * *$ & -8.75 & $-0.58 * *$ & -4.84 \\
\hline & Number of children (G3) & $-0.10 *$ & -2.56 & -0.04 & -1.36 \\
\hline & Number of siblings (G2) & $-0.13^{* *}$ & -5.03 & $-0.04 \dagger$ & -1.81 \\
\hline
\end{tabular}

Note: SHARE 2004 release 2, own calculations, unweighted. $n$ (likelihood) $=11$ countries, 5,595 households, 6,350 respondents, 7,825 dyads; $n$ (hours) $=11$ countries, 1,367 households, 1,437 persons, 1,520 dyads.

${ }^{\mathrm{a}}$ Unstandardized coefficients retrieved from four-level-model without context variable. ${ }^{\mathrm{b}} 1=$ very poor health, 5 $=$ very good health ${ }^{\mathrm{c}} 1=$ very good health, $5=$ very poor health. ${ }^{\mathrm{d}} 0=$ same house, $7=$ more than 500

kilometres \& abroad. The linearity of effects was proofed by non-parametric estimation before implementing a (quasi-) metric variable.

$* * p<0.01, * p<0.05, \dagger p<0.10$. 
Table 2: Help to parents: Contextual influences

\begin{tabular}{|c|c|c|c|c|}
\hline & \multicolumn{2}{|c|}{ Likelihood of help } & \multicolumn{2}{|c|}{$\log$ (hours) of help } \\
\hline & $\beta^{\mathrm{a}}$ & $z$ & $\beta^{\mathrm{a}}$ & $z$ \\
\hline \multicolumn{5}{|l|}{ Context (four separate full models) } \\
\hline Social expenditure $^{\mathrm{b}}$ & $0.14 * *$ & 7.78 & -0.10 & -1.58 \\
\hline$B I C$ & \multicolumn{2}{|c|}{$7,874.1$} & \multicolumn{2}{|r|}{$5,350.2$} \\
\hline Social services ${ }^{c}$ & $0.35^{* *}$ & 3.07 & $-0.05 * *$ & -2.86 \\
\hline$B I C$ & \multicolumn{2}{|c|}{$7,856.7$} & \multicolumn{2}{|r|}{$5,346.5$} \\
\hline Family expenditure $^{\mathrm{d}}$ & $0.17 * *$ & 3.51 & $-0.05 \dagger$ & -1.86 \\
\hline$B I C$ & \multicolumn{2}{|c|}{$7,872.6$} & \multicolumn{2}{|r|}{$5,349.5$} \\
\hline Family per state expenditure $^{\mathrm{e}}$ & $0.31 * *$ & 3.24 & $-0.10 \dagger$ & -1.85 \\
\hline$B I C$ & \multicolumn{2}{|c|}{$7,873.5$} & \multicolumn{2}{|r|}{$5,349.5$} \\
\hline
\end{tabular}

Note: SHARE 2004 release 2, own calculations, unweighted / OECD (2007a, b, c). $n$ (likelihood) $=11$ countries, 5,595 households, 6,350 respondents, 7,825 dyads; $n$ (hours) $=11$ countries, 1,367 households, 1,437 persons, 1,520 dyads.

${ }^{\text {a }}$ Unstandardized coefficients retrieved from separate four-level-models controlling for all individual and family characteristics (see Table 1). ${ }^{\mathrm{b}}$ Expenditure for services, transfers and goods in 100 US-Dollar per capita 2002. ${ }^{\mathrm{c}}$ Percentage of employees in sector $\mathrm{N}$ of the International Standard Industrial Classification. ${ }^{\mathrm{d}}$ Expenditure for services, transfers and goods in 1000 US-Dollar per capita 2002. ${ }^{\mathrm{e}}$ Percentage of countries' total spending. $* * p<0.01, * p<0.05, \dagger p<0.10$. 
Table 3: Help to children: Individual and family influences

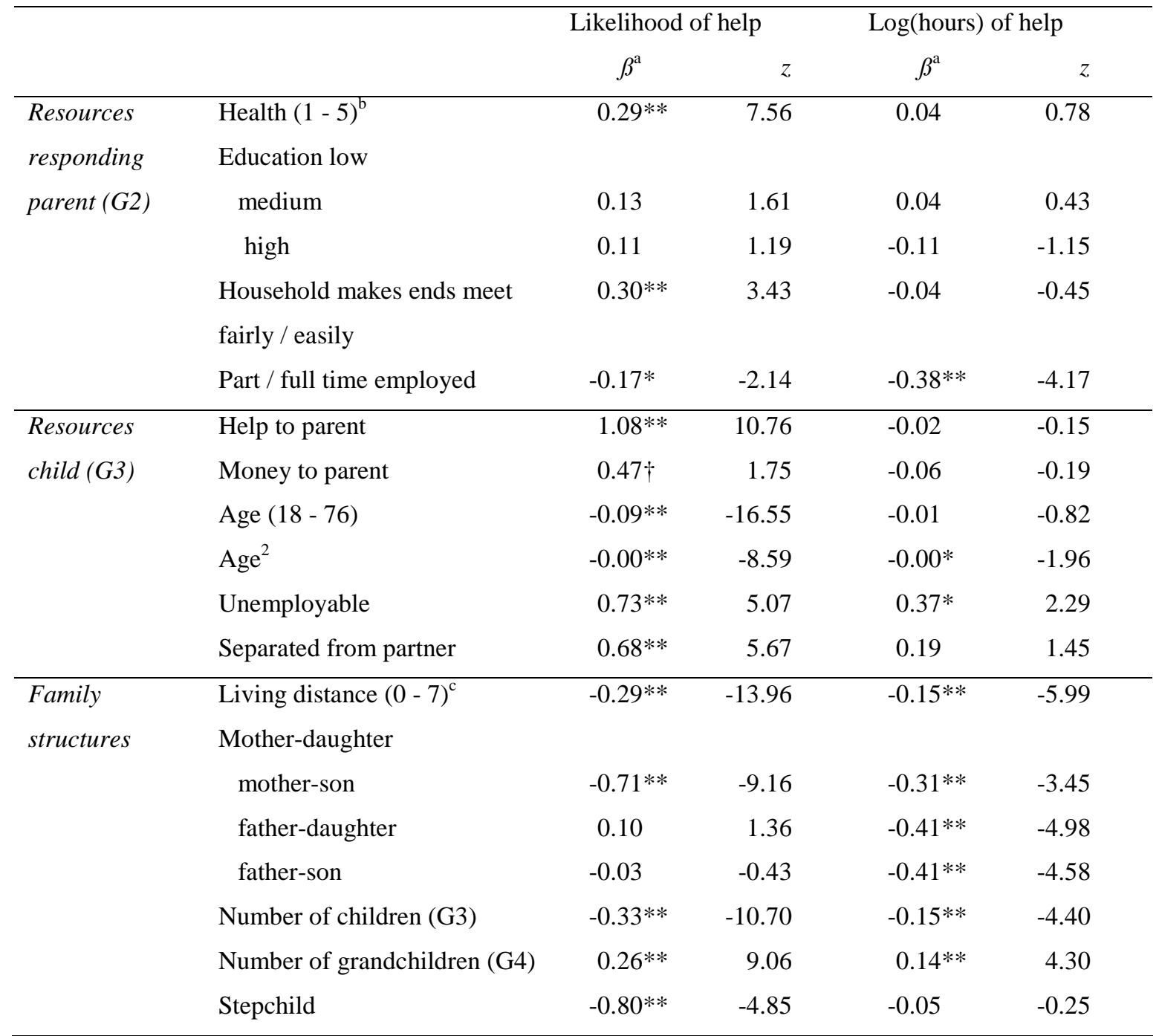

Note: SHARE 2004 release 2, own calculation, unweighted. $n$ (likelihood) $=11$ countries, 13,438 households, 19,148 respondents, 40,073 dyads; $n$ (hours) = 11 countries, 1,752 households, 2,030 persons, 2,584 dyads.

${ }^{\mathrm{a}}$ Unstandardized coefficients retrieved from four-level-model without context variable. ${ }^{\mathrm{b}} 1=$ very poor health, 5 $=$ very good health ${ }^{\mathrm{c}} 0=$ same house, $7=$ more than 500 kilometres \& abroad. The linearity of effects was proofed by non-parametric estimation before implementing a (quasi-) metric variable.

$* * p<0.01, * p<0.05, \dagger p<0.10$. 
Table 4: Help to children: Contextual influences

\begin{tabular}{|c|c|c|c|c|}
\hline & \multicolumn{2}{|c|}{ Likelihood of help } & \multicolumn{2}{|c|}{$\log$ (hours) of help } \\
\hline & $\beta^{\mathrm{a}}$ & $z$ & $\beta^{\mathrm{a}}$ & $z$ \\
\hline \multicolumn{5}{|l|}{ Context (four separate full models) } \\
\hline Social expenditure $^{b}$ & $0.48 * *$ & 12.06 & $-0.24 * *$ & -2.75 \\
\hline$B I C$ & \multicolumn{2}{|c|}{$17,316.3$} & \multicolumn{2}{|r|}{$9,980.2$} \\
\hline Social services $^{c}$ & $0.15^{* *}$ & 13.64 & $-0.08 * *$ & -3.81 \\
\hline$B I C$ & \multicolumn{2}{|c|}{$17,278.4$} & \multicolumn{2}{|r|}{$9,976.5$} \\
\hline Family expenditure $^{\mathrm{d}}$ & $0.22 * *$ & 12.75 & $-0.13^{* *}$ & -4.28 \\
\hline$B I C$ & \multicolumn{2}{|c|}{$17,302.0$} & \multicolumn{2}{|r|}{$9,974.7$} \\
\hline Family per state expenditure ${ }^{\mathrm{e}}$ & $0.41 * *$ & 12.23 & $-0.25 * *$ & -4.39 \\
\hline$B I C$ & \multicolumn{2}{|c|}{$17,315.1$} & \multicolumn{2}{|r|}{$9,974.0$} \\
\hline
\end{tabular}

Note: SHARE 2004 release 2, own calculation, unweighted / OECD (2007a; b; c). $n$ (likelihood) $=11$ countries, 13,438 households, 19,148 respondents, 40,073 dyads; $n$ (hours) = 11 countries, 1,752 households, 2,030 persons, 2,584 dyads.

${ }^{a}$ Unstandardized coefficients retrieved from separate four-level-models controlling for all individual and family characteristics (see Table 3). ${ }^{\mathrm{b}}$ Expenditure for services, transfers and goods in 100 US-Dollar per capita $2002 .{ }^{\mathrm{c}}$ Percentage of employees in sector $\mathrm{N}$ of the International Standard Industrial Classification. ${ }^{\mathrm{d}}$ Expenditure for services, transfers and goods in 1000 US-Dollar per capita 2002. ${ }^{\text {e }}$ Percentage of countries' total spending. $* * p<0.01, * p<0.05, \dagger p<0.10$. 
ANNEX

Table A1: Sample characteristics help to parent

\begin{tabular}{|c|c|c|c|c|c|c|}
\hline & $\mathrm{SE}$ & DK & NL & $\mathrm{BE}$ & FR & $\mathrm{DE}$ \\
\hline \multicolumn{7}{|l|}{ Dyad G2-G1 } \\
\hline G1 age & 82.4 & 81.5 & 82.9 & 81.9 & 81.8 & 80.7 \\
\hline G1 illness: health very good & 15.6 & 17.7 & 8.0 & 14.5 & 7.0 & 3.8 \\
\hline good & 19.2 & 25.8 & 30.7 & 32.6 & 29.9 & 31.2 \\
\hline fair & 40.3 & 32.9 & 41.2 & 35.1 & 36.2 & 41.9 \\
\hline poor & 20.3 & 15.1 & 16.9 & 14.0 & 21.9 & 16.9 \\
\hline very poor & 4.6 & 8.5 & 3.1 & 3.8 & 5.0 & 6.3 \\
\hline G1 partner & 31.0 & 35.3 & 31.5 & 35.2 & 40.4 & 34.7 \\
\hline Living distance same house & 0.3 & 0.4 & 0.4 & 0.5 & 1.3 & 5.6 \\
\hline$<1 \mathrm{~km}$ & 9.7 & 9.5 & 10.7 & 21.5 & 8.7 & 14.7 \\
\hline$<5 \mathrm{~km}$ & 15.8 & 17.9 & 24.8 & 26.0 & 14.1 & 22.3 \\
\hline$<25 \mathrm{~km}$ & 21.2 & 26.6 & 28.2 & 34.8 & 23.8 & 23.2 \\
\hline$<100 \mathrm{~km}$ & 20.9 & 22.0 & 18.8 & 12.3 & 16.7 & 15.5 \\
\hline$<500 \mathrm{~km}$ & 19.6 & 19.8 & 14.3 & 2.9 & 16.1 & 12.0 \\
\hline$>500 \mathrm{~km}$ & 6.8 & 0.4 & - & - & 10.6 & 2.1 \\
\hline$>500 \mathrm{~km} \&$ abroad & 5.7 & 3.4 & 2.8 & 2.1 & 8.7 & 4.7 \\
\hline Daughter-mother & 41.2 & 36.3 & 39.2 & 38.1 & 37.3 & 41.1 \\
\hline son-mother & 30.2 & 35.1 & 32.6 & 34.2 & 33.2 & 32.2 \\
\hline daughter-father & 16.5 & 12.9 & 16.9 & 14.6 & 15.4 & 15.2 \\
\hline son-father & 12.2 & 15.7 & 11.3 & 13.2 & 14.1 & 11.5 \\
\hline$n$ dyads & 955 & 496 & 797 & 1101 & 1041 & 764 \\
\hline \multicolumn{7}{|l|}{ Person G2 } \\
\hline Health very good & 39.6 & 30.7 & 24.6 & 26.0 & 23.2 & 22.3 \\
\hline good & 34.4 & 47.2 & 55.5 & 53.2 & 53.7 & 53.0 \\
\hline fair & 20.4 & 16.5 & 17.0 & 17.3 & 17.7 & 20.6 \\
\hline poor & 4.6 & 4.4 & 2.7 & 2.9 & 4.3 & 3.5 \\
\hline very poor & 1.0 & 1.2 & 0.2 & 0.6 & 1.1 & 0.6 \\
\hline Education low & 37.3 & 13.3 & 44.6 & 38.4 & 33.4 & 8.8 \\
\hline medium & 33.0 & 47.7 & 27.3 & 33.8 & 38.0 & 58.9 \\
\hline high & 29.7 & 39.1 & 28.1 & 27.8 & 28.6 & 32.3 \\
\hline Part / full time employed & 72.9 & 71.7 & 56.6 & 50.1 & 58.0 & 62.1 \\
\hline Money from G1 & 6.0 & 11.3 & 2.3 & 2.6 & 3.2 & 4.8 \\
\hline Gift from G1 & 37.6 & 22.6 & 21.3 & 29.1 & 21.4 & 23.6 \\
\hline Chance of bequest from G1 $<50 \%$ & 30.6 & 36.4 & 50.2 & 35.6 & 52.2 & 58.3 \\
\hline$>50 \%$ & 68.0 & 61.2 & 47.2 & 62.6 & 41.6 & 41.1 \\
\hline unknown & 1.4 & 2.5 & 2.6 & 1.8 & 6.2 & 0.6 \\
\hline Number of children (G3) & 2.5 & 2.1 & 2.2 & 2.0 & 2.3 & 1.7 \\
\hline Number of siblings & 2.0 & 2.2 & 3.3 & 2.4 & 2.8 & 1.8 \\
\hline$n$ persons & 785 & 407 & 663 & 896 & 818 & 623 \\
\hline \multicolumn{7}{|l|}{ Household } \\
\hline $\begin{array}{l}\text { Household makes ends meet fairly } \\
\text { / easily }\end{array}$ & 82.7 & 82.2 & 81.8 & 72.9 & 65.4 & 75.8 \\
\hline \multirow[t]{2}{*}{$n$ households } & 687 & 360 & 583 & 764 & 702 & 549 \\
\hline & $\mathrm{AU}$ & $\mathrm{CH}$ & $\mathrm{ES}$ & IT & GR & Total \\
\hline \multicolumn{7}{|l|}{ Dyad G2-G1 } \\
\hline G1 age & 81.8 & 83.0 & 82.9 & 83.5 & 82.0 & 82.1 \\
\hline G1 illness: health very good & 5.3 & 14.9 & 7.5 & 6.6 & 9.0 & 10.0 \\
\hline good & 28.1 & 33.1 & 32.7 & 24.6 & 34.6 & 29.2 \\
\hline fair & 47.0 & 38.1 & 38.1 & 40.4 & 38.6 & 38.8 \\
\hline poor & 17.5 & 11.6 & 15.9 & 20.2 & 13.8 & 17.1 \\
\hline very poor & 2.1 & 2.3 & 5.8 & 8.2 & 4.1 & 4.9 \\
\hline G1 partner & 37.8 & 39.7 & 34.1 & 33.5 & 40.3 & 35.5 \\
\hline Living distance same house & 6.0 & 4.6 & 4.9 & 10.9 & 10.2 & 3.7 \\
\hline$<1 \mathrm{~km}$ & 15.4 & 7.0 & 31.2 & 28.0 & 16.8 & 15.4 \\
\hline$<5 \mathrm{~km}$ & 20.3 & 15.9 & 23.2 & 18.0 & 18.3 & 19.8 \\
\hline$<25 \mathrm{~km}$ & 27.0 & 17.9 & 16.4 & 20.4 & 15.6 & 23.9 \\
\hline
\end{tabular}




\begin{tabular}{|c|c|c|c|c|c|c|}
\hline$<100 \mathrm{~km}$ & 17.1 & 30.1 & 10.2 & 11.0 & 13.2 & 16.4 \\
\hline$<500 \mathrm{~km}$ & 9.5 & 11.6 & 6.4 & 6.1 & 20.3 & 13.0 \\
\hline$>500 \mathrm{~km}$ & 0.9 & 8.2 & 4.7 & 4.2 & 3.5 & 3.8 \\
\hline$>500 \mathrm{~km} \&$ abroad & 3.9 & 4.6 & 3.1 & 1.4 & 2.2 & 4.0 \\
\hline Daughter-mother & 41.5 & 39.1 & 40.7 & 38.7 & 34.5 & 38.7 \\
\hline son-mother & 32.0 & 28.5 & 30.1 & 33.1 & 35.8 & 32.8 \\
\hline daughter-father & 13.4 & 18.9 & 16.2 & 17.2 & 14.0 & 15.4 \\
\hline son-father & 13.1 & 13.6 & 13.1 & 11.0 & 15.8 & 13.1 \\
\hline$n$ dyads & 434 & 302 & 452 & 589 & 894 & 7,825 \\
\hline \multicolumn{7}{|l|}{ Person G2 } \\
\hline Health very good & 23.7 & 45.1 & 19.3 & 13.6 & 39.4 & 27.8 \\
\hline good & 53.2 & 39.6 & 50.4 & 51.9 & 43.7 & 48.9 \\
\hline fair & 18.3 & 12.8 & 24.4 & 29.4 & 14.0 & 18.8 \\
\hline poor & 3.9 & 2.6 & 5.6 & 4.3 & 2.3 & 3.7 \\
\hline very poor & 0.9 & - & 0.3 & 0.8 & 0.7 & 0.7 \\
\hline Education low & 18.3 & 39.6 & 72.1 & 62.8 & 40.2 & 36.7 \\
\hline medium & 54.7 & 23.4 & 13.9 & 26.3 & 36.5 & 36.2 \\
\hline high & 27.0 & 37.0 & 13.9 & 10.9 & 23.3 & 27.0 \\
\hline Part / full time employed & 41.4 & 69.4 & 46.9 & 39.9 & 56.7 & 57.2 \\
\hline Money from G1 & 3.7 & 3.8 & 1.1 & 1.9 & 2.7 & 3.8 \\
\hline Gift from G1 & 17.5 & 38.3 & 13.9 & 16.3 & 19.3 & 24.1 \\
\hline Chance of bequest from G1 $<50 \%$ & 75.5 & 48.5 & 61.9 & 72.6 & 68.0 & 51.6 \\
\hline$>50 \%$ & 24.5 & 51.1 & 35.9 & 25.5 & 28.6 & 46.0 \\
\hline unknown & - & 0.4 & 2.1 & 1.9 & 3.4 & 2.4 \\
\hline Number of children (G3) & 2.0 & 2.1 & 2.4 & 2.0 & 1.8 & 2.1 \\
\hline Number of siblings & 2.0 & 2.5 & 2.9 & 2.3 & 2.1 & 2.4 \\
\hline$n$ persons & 355 & 235 & 373 & 486 & 709 & 6,350 \\
\hline \multicolumn{7}{|l|}{ Household } \\
\hline $\begin{array}{l}\text { Household makes ends meet fairly } \\
\text { / easily }\end{array}$ & 74.7 & 82.1 & 49.1 & 34.2 & 32.7 & 66.4 \\
\hline$n$ households & 328 & 212 & 344 & 442 & 624 & 5,595 \\
\hline
\end{tabular}

Table A2: Sample characteristics help to child

\begin{tabular}{lrrrrrr}
\hline & SE & DK & NL & BE & FR & DE \\
\hline Dyad G2-G3 & & & & & & \\
G2 help from G3 & 7.1 & 11.2 & 4.6 & 7.0 & 5.1 & 12.0 \\
G2 money from G3 & 0.6 & 0.5 & 0.3 & 0.5 & 0.5 & 2.1 \\
G3 age & 37.3 & 38.0 & 36.3 & 39.1 & 38.2 & 38.2 \\
G3 unemployable & 5.0 & 6.1 & 2.1 & 4.0 & 4.4 & 3.6 \\
G3 separated from partner & 5.1 & 6.6 & 4.2 & 6.5 & 5.9 & 5.7 \\
Living distance same house & 0.4 & 0.8 & 0.6 & 1.2 & 1.0 & 8.4 \\
$\quad<1 \mathrm{~km}$ & 8.7 & 8.4 & 13.9 & 15.3 & 9.7 & 11.1 \\
$\quad$ <5m & 18.0 & 16.1 & 29.0 & 26.8 & 15.7 & 18.2 \\
$\quad<25 \mathrm{~km}$ & 24.0 & 27.6 & 25.0 & 31.7 & 24.1 & 24.3 \\
$\quad<100 \mathrm{~km}$ & 19.1 & 23.0 & 17.9 & 17.8 & 18.3 & 14.6 \\
$\quad<500 \mathrm{~km}$ & 19.6 & 19.5 & 11.3 & 4.4 & 15.6 & 15.9 \\
$\quad>500 \mathrm{~km}$ & 6.6 & 0.4 & - & 0.1 & 11.0 & 4.1 \\
$\quad>500 \mathrm{~km} \&$ abroad & 3.6 & 4.3 & 2.2 & 2.8 & 4.7 & 3.4 \\
Mother-daughter & 26.8 & 27.2 & 27.3 & 28.3 & 28.6 & 27.3 \\
$\quad$ mother-son & 26.5 & 27.2 & 26.5 & 27.1 & 27.0 & 26.8 \\
$\quad$ father-daughter & 23.2 & 23.0 & 23.3 & 22.8 & 22.7 & 23.3 \\
$\quad$ father-son & 23.5 & 22.6 & 22.9 & 21.8 & 21.7 & 22.7 \\
Number of grandchildren (G4) & 1.4 & 1.3 & 1.2 & 1.4 & 1.4 & 1.1 \\
G3 stepchild & 12.6 & 11.0 & 3.4 & 4.3 & 3.1 & 4.7 \\
\hline$n$ dyads & 5,497 & 2,885 & 4,740 & 5,700 & 4,503 & 4,107 \\
\hline Person G2 & & & & & & \\
Health very good & 29.0 & 25.8 & 19.4 & 19.2 & 15.1 & 9.8 \\
$\quad$ good & 36.9 & 44.7 & 52.5 & 50.1 & 49.2 & 44.7
\end{tabular}




\begin{tabular}{|c|c|c|c|c|c|c|}
\hline fair & 25.4 & 22.3 & 23.6 & 24.4 & 28.2 & 33.1 \\
\hline poor & 7.0 & 4.9 & 4.1 & 5.2 & 6.0 & 10.3 \\
\hline very poor & 1.7 & 2.4 & 0.4 & 1.1 & 1.6 & 2.1 \\
\hline Education low & 52.2 & 25.0 & 57.4 & 52.1 & 51.2 & 18.2 \\
\hline medium & 27.1 & 44.8 & 23.4 & 25.6 & 31.0 & 56.8 \\
\hline high & 20.7 & 30.3 & 19.2 & 22.3 & 17.8 & 24.9 \\
\hline Part / full time employed & 41.1 & 37.2 & 27.1 & 21.0 & 27.3 & 26.6 \\
\hline Number of children (G3) & 2.6 & 2.5 & 2.6 & 2.5 & 2.6 & 2.2 \\
\hline $\mathrm{n}$ persons & 2,413 & 1,276 & 2,147 & 2,736 & 2,116 & 2,078 \\
\hline \multicolumn{7}{|l|}{ Household } \\
\hline $\begin{array}{l}\text { Household makes ends meet fairly / } \\
\text { easily }\end{array}$ & 79.2 & 79.0 & 79.6 & 69.4 & 65.6 & 74.7 \\
\hline \multirow{2}{*}{$n$ households } & 1,719 & 897 & 1,418 & 1,857 & 1,467 & 1,389 \\
\hline & $\mathrm{AU}$ & $\mathrm{CH}$ & ES & IT & GR & Total \\
\hline \multicolumn{7}{|l|}{ Dyad G2-G3 } \\
\hline G2 help from G3 & 10.4 & 5.3 & 4.9 & 5.7 & 11.6 & 7.6 \\
\hline G2 money from G3 & 2.4 & 0.7 & 0.9 & 1.0 & 6.3 & 1.3 \\
\hline G3 age & 38.3 & 37.9 & 38.5 & 38.6 & 39.7 & 38.1 \\
\hline G3 unemployable & 6.0 & 1.9 & 2.2 & 1.6 & 2.8 & 3.7 \\
\hline G3 separated from partner & 7.0 & 5.8 & 3.4 & 3.2 & 4.0 & 5.3 \\
\hline Living distance same house & 10.4 & 4.0 & 4.2 & 10.4 & 13.7 & 4.2 \\
\hline$<1 \mathrm{~km}$ & 12.8 & 10.9 & 30.9 & 21.1 & 17.5 & 14.0 \\
\hline$<5 \mathrm{~km}$ & 19.5 & 17.7 & 21.5 & 22.0 & 17.2 & 20.7 \\
\hline$<25 \mathrm{~km}$ & 26.7 & 29.0 & 17.2 & 22.0 & 18.7 & 24.9 \\
\hline$<100 \mathrm{~km}$ & 15.2 & 20.2 & 9.9 & 9.3 & 7.5 & 16.1 \\
\hline$<500 \mathrm{~km}$ & 10.8 & 12.8 & 8.6 & 4.5 & 15.9 & 12.7 \\
\hline$>500 \mathrm{~km}$ & 1.3 & 4.3 & 4.4 & 7.6 & 4.5 & 4.0 \\
\hline$>500 \mathrm{~km} \&$ abroad & 3.3 & 1.0 & 3.3 & 2.9 & 5.0 & 3.4 \\
\hline Mother-daughter & 30.5 & 27.4 & 27.6 & 29,1 & 30.0 & 28.1 \\
\hline mother-son & 27.5 & 26.0 & 29.1 & 27.3 & 27.8 & 27.1 \\
\hline father-daughter & 21.8 & 23.6 & 22.5 & 22.9 & 21.7 & 22.8 \\
\hline father-son & 20.3 & 23.0 & 20.8 & 20.7 & 20.5 & 22.0 \\
\hline Number of grandchildren (G4) & 1.2 & 1.1 & 1.3 & 1.3 & 1.3 & 1.3 \\
\hline G3 stepchild & 3.3 & 1.0 & 0.9 & 0.7 & 1.1 & 4.8 \\
\hline$n$ dyads & 2,703 & 1,398 & 2,805 & 2,751 & 2,984 & 40,073 \\
\hline \multicolumn{7}{|l|}{ Person G2 } \\
\hline Health very good & 16.3 & 31.7 & 7.7 & 7.2 & 19.1 & 17.9 \\
\hline good & 45.0 & 47.6 & 40.7 & 41.3 & 38.5 & 44.9 \\
\hline fair & 30.4 & 17.8 & 36.8 & 39.6 & 33.5 & 28.6 \\
\hline poor & 7.0 & 2.7 & 12.1 & 10.2 & 6.9 & 7.0 \\
\hline very poor & 1.3 & 0.2 & 2.7 & 1.8 & 2.0 & 1.6 \\
\hline Education low & 31.5 & 55.2 & 88.0 & 83.2 & 72.0 & 52.3 \\
\hline medium & 48.4 & 21.5 & 6.0 & 13.0 & 18.5 & 29.3 \\
\hline high & 20.2 & 23.3 & 6.0 & 3.8 & 9.5 & 18.4 \\
\hline Part / full time employed & 15.6 & 33.8 & 15.8 & 11.7 & 19.7 & 25.4 \\
\hline Number of children (G3) & 2.3 & 2.5 & 2.9 & 2.5 & 2.3 & 2.5 \\
\hline n persons & 1,338 & 656 & 1,333 & 1,451 & 1,604 & 19,148 \\
\hline \multicolumn{7}{|l|}{ Household } \\
\hline $\begin{array}{l}\text { Household makes ends meet fairly } \\
\text { / easily }\end{array}$ & 74.0 & 81.2 & 41.7 & 35.3 & 28.7 & 65.0 \\
\hline$n$ households & 1,002 & 467 & 1,015 & 1,022 & 1,185 & 13,438 \\
\hline
\end{tabular}

Note: SHARE release 2, own calculations, unweighted percentages \& means.

Order of variables according to measurement levels. 
Table A3: Macro indicators

\begin{tabular}{lcccc}
\hline 2002 & $\begin{array}{c}\text { Social expenditure } \\
\text { (USD/capita) }\end{array}$ & $\begin{array}{c}\text { Social services } \\
\text { (\% of employees in } \\
\text { health and social } \\
\text { services) }\end{array}$ & $\begin{array}{c}\text { Family expenditure } \\
\text { (USD/capita) }\end{array}$ & $\begin{array}{c}\text { Proportion of } \\
\text { family expenditure } \\
\text { (\% of total) }\end{array}$ \\
\hline SE & $8,639.5$ & 18.7 & & 6.0 \\
DK & $8,153.0$ & 18.0 & $1,167.4$ & 7.0 \\
NL & $6,231.8$ & 14.7 & 492.3 & 3.4 \\
BE & $7,666.1$ & 12.1 & 777.6 & 5.3 \\
FR & $7,827.9$ & 10.1 & 827.4 & 5.6 \\
DE & $7,324.0$ & 10.4 & 530.7 & 4.1 \\
AU & $7,725.3$ & 8.6 & 891.1 & 5.9 \\
CH & $6,311.2$ & 10.7 & 465.8 & 4.0 \\
ES & $4,809.0$ & 5.6 & 213.6 & 2.3 \\
IT & $6,545.9$ & 6.1 & 312.2 & 2.4 \\
GR & $4,077.6$ & 4.6 & 231.0 & 2.4 \\
\hline
\end{tabular}

Note: OECD (2007a, b, c). 